\title{
GROUNDING INNOVATION: HOW EX-ANTE PROHIBITIONS AND $E X$-POST ALLOWANCES IMPEDE COMMERCIAL DRONE USE
}

\begin{abstract}
Timothy M. Ravich*
Unmanned aerial vehicles-"UAVs" or "drones"-are increasingly becoming a mainstream commercial phenomenon and tool for a vast range of commercial consumer, prosumer, and professional activities. Given advances in automation and miniaturization generally-and flight control stability and autopilot systems specifically-anyone can now fly in any airspace at any time by operating hand-held fixed-wing aircraft or quadcopters with little more than an ordinary smartphone or tablet. As such, sales of store-bought drones number in the millions, 1 corresponding to the wide range of civil applications and value propositions that UAVs offer.

Though civil drones are an attractive business investment, substantial regulatory headwinds confront the drone industry as startups endeavor to get to market and scale quickly. This
\end{abstract}

* Assistant Professor, University of Central Florida, Department of Legal Studies. Professor Ravich was general counsel for PrecisionHawk, a multinational precision-agriculture drone company, during its successful efforts to obtain one of the first civil drone authorizations in the United States. He is also author of Commercial Drone Law: Digest of U.S. AND Global UAS Rules, Policies, and Practices (American Bar Association 2017) and served as Principal Investigator of Evolving Law on Airport Implications by Unmanned Aerial Systems, a 2017 project sponsored by the National Academy of Sciences, Engineering, and Medicine, Airport Cooperative Research Program. Comments invited at timothy.ravich@ucf.edu.

1 Ashley Halsey III, Drone Sales Soaring this Christmas, Capping a Record Year for the Industry, WASH. PosT (Dec. 23, 2016), https:/www.washingtonpost.com/local/trafficandcommuting/drone-salessoaring-this-christmas-capping-a-record-year-for-the-industry/2016/12/22/ 09d81c94-c862-11e6-85b5-76616a33048d_story.html [perma.cc/WM35D9SZ]. 
is so notwithstanding-or perhaps even because of - the celebrated abilities of most small UAVs to fly boundlessly and collect and record information from nearly any vantage point. Drones are a classically disruptive technology of social, economic, and legal norms. Their operations raise novel and valid concerns in many of these areas, particularly in terms of safety and privacy. Consequently, regulators have respondedand they should. But federal, state, and local lawmakers alike have responded with policy interventions that are too often premature (or untimely) and overly rigid, discouraging the many beneficial uses of UAV technology. In fact, on the basis of ephemeral fears rather than data, regulators initially put in place overbroad and permission-based restraints that were tantamount to a de facto ban on all drone operations.

This Article critiques the underlying thinking and approach that federal regulators have taken with respect to civil drones and argues that commercial UAVs should be a "permissionless innovation." This Article posits that a better alternative to a top-down, ex-ante regulatory scheme is to broadly allow commercial UAVs and to deal with careless or reckless or nefarious operators and operations on a case-bycase, ex-post basis. In doing so, this Article aims to present lessons learned in the context of commercial UAVs so that inefficiencies and paternalistic rulemaking can be avoided in the regulation of other innovations associated with the Internet of Things, including urban air mobility and electric verticaltakeoff-and-landing technologies-otherwise known as flying cars - that are just around the corner.

I. Introduction 497

II. The Drone Economy............................................. 504

A. From Hardware to Software .............................506

B. Civil UAV Market Segments.............................5510

C. Business Ethics and Regulatory Ambiguity .......520

III. The UAV Legal Environment.................................. 532

A. Federalism and Preemption..............................533

B. New Drone Business Issues and Common Law Resilience.

IV. Critiquing the UAV Regulatory Environment......... 551 
A. Regulatory Timing.

B. Regulatory Enforcement

C. Regulatory Decisions with Incomplete Data ......570

D. Regulatory Overreach: Chevron Deference....

V. Conclusion

.580

\section{INTRODUCTION}

Unmanned aerial vehicles-also referred to as "UAVs" or "drones"-are revolutionizing business. In fact, as an Oppenheimer emerging technologies and services report emphatically stated, "[t]he emergence of consumer and commercial UAVs is inevitable."2 Agreeing with this assertion, this Article explains how drones are becoming an increasingly mainstream tool for a vast range of commercial consumer, prosumer, and professional activities. This Article further seeks to show how and why ex-ante prohibitions and precautionary thinking among lawmakers with respect to drone-based businesses have impeded the full potential of UAV innovation to date, both in theory and in practice.

Like self-driving cars, digital drugs, wearable technologies, and other wireless and networked devices that fall under the classification "Internet of Things" ("IoT"), drones are a "smart" technology that exemplify machine learning. At the center of the drone revolution are airplanes equipped with artificially intelligent and sophisticated sensor suites, high definition cameras, global positioning systems, and algorithmic-driven, cloud-based software solutions that capture, store, and analyze big data. The use of drones for military purposes, including "signature strikes" or intelligence, surveillance, and reconnaissance missions, initially clouded public perception and acceptance of the technology. ${ }^{3}$ Since approximately 2006 ,

2 Andrew Uerkwitz et Al., Oppenheimer \& Co., Drone Industry REPORT: "I"S IN THE SKY 3 (2016) [hereinafter DRONE INDUSTRY REPORT].

3 Use of combat drones raises legal issues involving the law of armed conflict, sovereignty, and cyberwarfare-issues beyond the scope of this Article. See generally Charles Jarnot, History, in InTRODUCTION TO Unmanned Aircraft Systems 1, 1-15 (Richard K. Barnhart et al. eds., 2012); see also P. W. Singer, WirED FOR WAR (2009). 
however, investment in civil and commercial drones has been vigorous and the public perception of drones-even the militarized connotation of the word drone itself-has softened somewhat. "Moving at the pace of the smartphone industry, not the aerospace industry, drones went from hackers' devices to hobbyists' instruments to toys costing less than $\$ 100$ at your local big-box store in less than four years-perhaps the fastest transfer of technology from CIA to Costco in history." 4

The wide-spread availability and affordability of microand small drones-i.e., drones weighing under $.55 \mathrm{lbs}$., or between $.55 \mathrm{lbs}$. and $55 \mathrm{lbs}$., respectively-has opened low altitude airspace above every community in every nation around the world to countless new users and uses, including for hobby, recreational, and commercial purposes, in less than a decade. Given advances in automation and miniaturization generally, and flight control stability and autopilot systems specifically, anyone can now fly in any airspace at any time by operationalizing hand-held fixed-wing aircraft or quadcopters out-of-the-box with little more than an ordinary smartphone or tablet. The end user is everybody, from proprietors to prisoners. 5 As such, sales of store-bought drones number in the millions, corresponding to the extensive number of civil applications and value propositions that UAVs offer. The drone industry includes precision agriculture, aerial photography and journalism, urban planning, real estate, insurance, pipeline and railroad monitoring, construction, emergency management, power line inspection, educational and academic uses, entertainment, and-perhaps most rousing-logistics and telecommunications.

4 Chris Anderson, The Drone Economy, Harv. Bus. Rev., May 2017, at 5 .

5 Niraj Chokshi, South Carolina Inmate May Have Used Drone in Prison Escape, Officials Say, N.Y. Times (July 7, 2017), https://www.nytimes.com/2017/07/07/us/drone-inmate-escape.html; Michael S. Rosenwald, Prisons Try to Stop Drones from Delivering Drugs, Porn and Cellphones to Inmates, WAsH. Post (Oct. 13, 2016), https://www.washingtonpost.com/local/prisons-try-to-stop-drones-fromdelivering-drugs-porn-and-cellphones-to-inmates/2016/10/12/645fb102800c-11e6-8d0c-fb6c00c90481_story.html [perma.cc/XT2V-UUGM]. 
Only four years after Jeff Bezos created buzz on 60 Minutes by announcing that his company would deliver up to eightysix percent of its entire inventory by drone, 6 Amazon applied for a patent in 2017 "for beehive-like towers that . . . serve as multi-level fulfillment centers for its delivery drones to take off and land."7 Meanwhile, with Project Aquila and Project Loon, Facebook and Google, respectively, are experimenting with unmanned networks of high-altitude long-endurance drones ("HALEs") and flying stratospheric balloons to serve as floating internet connections 65,000 feet above remote and underserved parts of the planet. 8 Closer to the ground (i.e., two hundred feet above the grass), AT\&T has deployed its Flying COW-"Cell on Wings"- to assist with post-Hurricane Maria relief efforts in Puerto Rico. 9 AT\&T's Pulse Vapor 55 is a tethered-drone fitted with LTE radios and antennas to function like a temporary cell service tower in the sky, restoring voice, data, and internet service to isolated areas. 10 Taken together, these drone-centered business activities

660 Minutes: Amazon's Jeff Bezos Looks to the Future (CBS television broadcast Dec. 1, 2013), https://www.cbsnews.com/news/amazons-jeffbezos-looks-to-the-future/ [perma.cc/54YD-A697]. Contra Paul Ziobro, Teamsters Tell UPS: No Delivery Drones or Driverless Trucks, Wall ST. J. (Jan. 24, 2018, 7:00 AM), https://www.wsj.com/articles/teamsters-tell-upsno-drones-or-driverless-trucks-1516795200 [perma.cc/EY26-QYAQ].

7 Kaya Yurieff, Amazon Patent Reveals Drone Delivery 'Beehives', CNN TECH (June 23, 2017, 9:44 AM), http://money.cnn.com/2017/ 06/23/technology/amazon-drone-beehives/index.html [perma.cc/FF88L3GW].

8 See e.g., Project Loon, https://x.company/loon/ [perma.cc/8WZFBAMJ]; Darrell Etherington, Facebook's Aquila Drone Completes Its Second Test Flight, Lands Well This Time, TEchCRUnCH (June 29, 2017), https://techcrunch.com/2017/06/29/facebooks-aquila-drone-completes-itsecond-testflight-lands-well-this-time/ [perma.cc/6SQW-Z5Z5].

9 See Scott Berinato, Flying COWs and Other Drone Apps, HARv. Bus. REV. (May 17, 2017), https://hbr.org/2017/05/flying-cows-and-other-droneapps [perma.cc/ZK9F-G6L8]; see also David Shepardson, FAA Approves AT\&T Drone in Puerto Rico for Cellular Service, REuTERs (Nov. 17, 2017, 2:31 PM), https://www.reuters.com/article/us-storm-maria-telecoms/faaapproves-att-drone-in-puerto-rico-for-cellular-service-idUSKBN1DH2I2 [perma.cc/8D5W-ET7J].

$10 I d$. 
reveal the core value of commercial drones: data. As Chris Anderson, CEO of 3D Robotics and former editor of Wired, wrote, "reality capture" makes drones an interesting business case. 11

More than anything, drones are collection vehicles. Their ability to amass data from a unique, valuable perspective (above, but not too far above) fast and at low cost makes them ideal collectors. Any drone strategy must consider not only the drone itself but also data management, which means bringing innovation to the cloud. 12

That is, with a drone,

the process of digitizing the physical world by scanning it inside and out-from the ground and the air-has finally matured into a technology that's transforming business. It can be seen in small ways in Google Maps, where data is captured by satellites, airplanes, and cars, and presented in both 2-D and 3D. Now that kind of mapping, initially designed for humans, is done at much higher resolution in preparation for the self-driving car, which needs highly detailed 3-D maps of cities in order to efficiently navigate. The methods used to create such models of the real world are related to "motion capture" technology, which drives movies and video games today. Normally that requires bringing the production to the scanners-putting people in a large room outfitted for scanning and then creating the scene. But drones flip that process, allowing businesspersons to bring the scanners to the scene. Drones involve regular cameras (and some smart software) precisely revolving around objects to create photo-realistic digital models. 13

As a consequence of the data collection capacity of drones, businesspersons in the drone space, rather than merely seeing "airplanes without pilots," see an "internet of flying things"

11 Anderson, supra note 4, at 3.

$12 \mathrm{Id}$. at 7.

13 Id. at 3 . 
made up of "smartphones with propellers" that "offer, literally, a new view into business: Their low-overhead perspective is bringing new insights and capabilities to fields and factories alike."14 Maybe most compelling is the fact that drones are an exotropic technology-their value is derived from ever-evolving software rather than fixed or static hardware; and thus, drones will rise in value over time rather than gravitate toward obsolescence. 15

Though UAVs are an attractive business investment, substantial regulatory headwinds confront the drone industry as startups endeavor to get to market and scale quickly. This is so notwithstanding - or perhaps because of - the celebrated abilities of most small UAVs to fly boundlessly and collect and record information from nearly any vantage point. Drones are a classically disruptive technology of social, economic, and legal norms. Their operations raise novel and valid concerns in many of these areas, particularly in terms of safety and privacy. 16 Indeed, with the Federal Aviation Administration (the "FAA") projecting the integration of seven million drones into the airspace by 2020,17 the question of how drones can fly safely in a national airspace system originally designed for manned flight is both daunting and critical.18 The risk that

14 Id. at 4.

$15 I d$. at 8 ("[R]ather than follow the traditional long decay slope from point of purchase, connected devices improve in utility for as long as they can. In the case of drones, new abilities, from improved performance to new autonomous features, just appear overnight via 'over the air' upgrades.").

16 See, e.g., Paul Mozur, China Drone Maker Says It May Share Data with State, N.Y. Times (Apr. 20, 2016), https://www.nytimes.com/2016/04/21/world/asia/dji-drones-china.html ("Already, DJI's user agreement flags the possibility that whoever flies a drone may not be flying it alone. It reads: 'Please note that if you conduct your flight in certain countries, your flight data might be monitored and provided to the government authorities according to local regulatory laws.").

17 Fed. Aviation Admin., FAA Releases 2016 to 2036 Aerospace Forecast, https://www.faa.gov/news/updates/?newsId=85227\&cid=TW414 [perma.cc/429D-GZAB] (last modified Mar. 24, 2016, 12:10 PM).

18 See generally Doug Lenz \& Dae Suh, Navigating Quickly Crowding Skies, Airport MAG., Sept. 2016, at S12-13 ("Airports across the country are seeing record passenger counts .... As airspace becomes increasingly 
novice or nefarious UAV operators will collide or interfere with traditional aircraft is not merely a hypothetical worry. The title of a recent article from the United Kingdom-"Idiot Flies Drone Alongside Flybe Jet Landing at Newquay Airport"-illustrates the point. 19 In addition to operational issues, UAV operations are stretching common law doctrines related to, for instance, intellectual property, negligence, and trespass, as well as constitutional principles under the First, Second, Fourth, Fifth, and Tenth Amendments. Consequently, regulators have responded-and they should.

But, federal, state, and local lawmakers alike have responded with policy interventions that too often are premature (or untimely) and overly rigid, discouraging the many beneficial uses of UAV technology. In fact, on the basis of ephemeral fears rather than data, regulators initially put in place overbroad, permission-based restraints that were tantamount to a de facto ban on all drone operations. ${ }^{20}$ For example, in July 2013, Virginia became the first state in the nation to enact drone legislation-or more accurately, antidrone legislation. 21 The Virginia law imposed a two-year moratorium on the flight of all state or local law enforcement drones for the purpose of gathering evidence pursuant to a search warrant. 22 As other states also began to implement

crowded with additional planes, and with the upsurge in UAS, aerospace officials at NASA say the current Air Traffic Control System will not be equipped to handle the predicted volume or variety of aircraft expected in 2035 and beyond.”).

19 Gareth Corfield, Idiot Flies Drone Alongside Flybe Jet Landing at Newquay Airport, REgister (Aug. 11, 2016, 12:06 PM), http://www.theregister.co.uk/2016/08/11/drone_near_miss_flybe_newquay_ airport/ [perma.cc/8RML-TZWJ] ("Although the near-miss was reported to police, a search of the area revealed no trace of the drone or its operator.").

20 See e.g., Adam D. Thierer, The Internet of Things and Wearable Technology: Addressing Privacy and Security Concerns Without Derailing Innovation, 21 RicH. J.L \& TECH. 6, 68 (2015).

21 See e.g., Jason Koebler, Virginia Becomes First State to Pass Drone Regulations, U.S. NEWS \& WorLD REP. (Feb. 5, 2013, 4:42 AM), https://www.usnews.com/news/articles/2013/02/05/virginia-becomes-firststate-to-pass-drone-regulations-.

222013 Va. Acts, ch. 755. 
restrictive drone laws, Congress addressed pent-up demand by the business drone community by explicitly directing the FAA to implement a plan to integrate UAVs into the national airspace system (the "NAS") "not later than" September 30, 2015. 23 However, the FAA did not produce any permissive UAS regulations until almost a year after this deadline (and four years after the law setting the deadline was passed). Consequently, unscrupulous UAV operators were left alone to profit in a wild west-type marketplace while an emerging and conscientious drone business community was left abandoned by regulators for years. A patchwork of inconsistent laws respecting the use of drones for business purposes resulted.

In 2016, the FAA ultimately codified a national, uniform set of regulations-14 C.F.R. Part 107 ("Part 107")—for the operation of small UAVs (i.e., UAVs weighing between .55 lbs. and $55 \mathrm{lbs}$.). ${ }^{24}$ However, drone makers and businesses remain unsatisfied about the pace of commercial drone lawmaking and the permission-based restrictions now in place. In fact, the law continues to disallow (subject to a waiver process) some of the most valuable operations for UAV businesses, including operations at night, over people, beyond visual line of sight ("BVLOS"), from a moving vehicle, and above a 400feet altitude ceiling. The manner in which regulators have (or have not) adapted to the drone revolution over the last decade - from moratoria to less restrictive schema under Part 107-are instructive for investors of IoT advancements that are rapidly changing the business law landscape.

This Article critiques the underlying thinking and approach that regulators have taken with respect to civil drones and argues that commercial UAVs should be a "permissionless innovation" such that "the burden of proof rests on those who favor precautionary regulation; they must explain why ongoing experimentation with IoT technologies should be prevented preemptively by force of law." 25 As a predicate to this argument, Part II of this Article overviews

23 FAA Modernization and Reform Act of 2012, Pub. L. No. 112-95, $\S 332$ (a)(3), 126 Stat. 11 (2012).

24 Small Unmanned Aircraft Systems, 14 C.F.R. pt. 107 (2018).

25 Thierer, supra note 20, at 3. 
the market segments, investors, and companies that make up the drone economy and details the business applications that drones offer an emerging commercial UAV space. Part II also discusses business ethics quandaries that rule-following (i.e., risk-averse) commercial UAV firms confront when no rules or only uncertain or ambiguous policies exist. Part III then sets out the main business law issues that will shape and are being shaped by the commercial UAV industry and around which UAV stakeholders must navigate, including federalism, preemption, and the common law. Part IV then presents four examples of faults in the regulatory approach thus far taken by the FAA with respect to commercial drones. Finally Part V concludes that a better alternative to a top-down UAV regulatory scheme is one that generally allows commercial UAV operations and instead addresses careless, reckless, or nefarious operators and operations on a case-by-case ex-post basis. In doing so, this Article aims to present some lessons learned in the specific context of commercial UAVs so that inefficiencies and paternalistic rulemaking is avoided in other areas where the law interfaces with IoT devices.

\section{THE DRONE ECONOMY}

Stories about hobbyists, small businesses, and major corporations using - or wanting to use-drones for exciting and unexpected purposes are in the news every day. 26 For example, in November 2017, an Illinois university delivered college admissions acceptance letters by drone to high school students. 27 Only a few years earlier, Dominos delivered the world's first pizza-by-drone in New Zealand,28 before which 7-

26 See, e.g., Laura Stampler, 8 Weirdest Ways People Are Using Drones, Time (July 14, 2014), http://time.com/2981749/8-of-the-weirdest-wayspeople-are-using-drones/ [perma.cc/EFP4-HTG5].

27 See Lewis University Uses UAS to Deliver Acceptance Letters to Local

High School Students, AUVSI (Nov. 15, 2017), http://www.auvsi.org/industry-news/lewis-university-uses-uas-deliveracceptance-letters-local-high-school-students [perma.cc/6M7T-4PHA].

28 See David Reid, Domino's Delivers World's First Ever Pizza by Drone, CNBC, https://www.cnbc.com/2016/11/16/dominos-has-delivered-the- 
Eleven, in tandem with drone maker Flirtey, made the first commercial delivery of any kind in the United States (a chicken sandwich, donuts, coffee, candy, and Slurpees) to a private residence in Nevada. 29 In 2014, a London-based sushi restaurant deployed "iTable," a sort of robot-waiter-drone, to serve its diners. 30 Meanwhile, a club in Las Vegas, for a mere $\$ 20,000$, provided pool-side bar service via a small quadcopter. 31 Even Pope Francis has a drone of his very own, a gift from a Jesuit school in Rome that is "tricked out with the colors of the Vatican flag (yellow and white) and bears the papal emblem ... the drone is supposed to represent the values of technology in the service of man."'32 Some of these applications are gimmicky or just for fun while others are designed to show that a particular business application is feasible. Altogether, the underlying value proposition in each instance is the operational agility of UAVs and the economic opportunity they provide by flying with fewer logistical, infrastructure, and human costs and constraints than are involved with traditional manned aircraft and helicopters.

worlds-first-ever-pizza-by-drone-to-a-new-zealand-couple.html [perma.cc/ 7TGB-M48F] (last updated Nov. 16, 2016, 9:02 AM).

29 See, e.g., Andrew Liptak, 7-Eleven Just Made the First Commercial Delivery by Drone, VERGE (July 23, 2016, 10:22 AM), https://www.theverge.com/2016/7/23/12262468/7-11-first-retailer-deliverfood-drone [perma.cc/5BHZ-H8YA].

30 Sean Fitz-Gerald, Sushi Restaurant Tests Drone-Driven Food Delivery, MASHABLE (June 12, 2013), http://mashable.com/2013/06/12/sushidrone-delivery [perma.cc/GKX8-JQRY].

31 Laura Stampler, This Club Is Offering Poolside Drone Bottle Service, Time (June 19, 2014), http://time.com/2901197/drone-bottle-service/ [perma.cc/86RT-2SPZ].

32 Abby Ohlheiser, Pope Francis Has a Drone of His Very Own, Wash. Post (Apr. 30, 2015), https://www.washingtonpost.com/news/acts-offaith/wp/2015/04/30/pope-francis-has-a-drone-of-his-very-own/ [perma.cc/ HJD2-FDGW]. 


\section{A. From Hardware to Software}

Eccentric and aspirational drone users and uses aside, ${ }^{33}$ the fundamental value of a UAV lies in its small and miniaturized hardware, specifically an aerial platform (typically with a flying camera) that can perform "dirty, dull, and dangerous" missions more nimbly and cost-effectively than manned aviation assets. 34 Given the ability of drones to fly just above the ground, outdoors, indoors, and even underground 35 governments around the world are recognizing drones as a tool that can upend society-for better or worse. In India, for example, voting officials outfitted five drones with cameras to monitor proper election processes. 36 Meanwhile, the United Arab Emirates is intent on using drones to deliver ID cards, drivers licenses, passports, and medicine. Additionally, the UAE hosts an annual tournament titled "Drones for Good," offering one million dollars to private firms and entrants for the idea that best encourages useful and positive civil applications of drone technology. ${ }^{37}$ Indeed,

33 See, e.g., Cat Drone Inventor Works on Flying Cows, BBC News (Aug. 3, 2016), http://www.bbc.com/news/technology-36954689 [perma.cc/5FC4GWQ9] (reporting that a man "best known for turning his dead cat Orville into a drone [now] aims to see humans riding on their animals in the sky").

34 Bernard Marr, The 4 Ds of Robotization: Dull, Dirty, Dangerous and

Dear, FoRBES (Oct. 16, 2017, 12:28 AM), https://www.forbes.com/sites/bernardmarr/2017/10/16/the-4-ds-of-

robotization-dull-dirty-dangerous-and-dear/.

35 See Mike Cherney, Drones Are Now Operating Underground, WaLL ST. J. (Nov. 9, 2017, 9:12 PM), https://www.wsj.com/articles/miners-aimvery-sci-fidrones-at-dark-dangerous-places-1509886805 [perma.cc/UNE56DM4].

36 See, e.g., Civic Polls in Mathura to Be Conducted using Drones with Cameras, NDTV (Nov. 26, 2017, 12:38 AM), https:/www.ndtv.com/indianews/civic-polls-in-mathura-to-be-conducted-using-drones-with-cameras1780045 [perma.cc/54W5-9E5D].

37 See The UAE Drones for Good Award, Drones For GooD http://www.dronesforgood.ae/ [perma.cc/9LRR-VG3B]; see also Flasal J. Abbas, Drones for Good: UAE Honors Peaceful-Purpose Innovators, HuFFPost, https://www.huffingtonpost.com/faisal-abbas/drones-for-gooduae-honor_b_6640152.html [perma.cc/2N5Z-F822]. 
the full potential for drones to support public health, safety, and welfare is yet to be realized.

Non-governmental organizations and private firms around the world are also answering the call to explore and exploit welfare enhancing uses of drones. For example, a Swiss team-Flyability - won the inaugural UAE Drones for Good prize by demonstrating a gimbal on a collision-proof searchand-rescue drone designed to operate safely in inaccessible environments. 38 Delaware-based WeRobotics is using seed money from the U.S. Agency for International Development to combat the Zika virus by developing drones that can carry sterile mosquitoes into hard-to-reach zones. 39 Elsewhere, academics and scientists from the Ocean Alliance are working with roboticists to operate "SnotBot," a drone that hovers above whales and lowers a petri dish to collect the mucus-like substance exhaled out of the mammals' blowholes, helping researchers collect data about whale behavior without the disruption and noise caused by boats or helicopters. 40 Finally, the San Francisco-based automated logistics firm Zipline is working with the Rwandan government to deliver blood and vaccines by drone on demand, offering "the world's only drone delivery system at national scale to send urgent medicines like blood to patients, no matter where they live. ${ }^{41}$

38 See, e.g., Nadeem Hanif, Swiss Search-and-Rescue Drone Wins UAE Competition, NATIONAL (Feb. 8, 2015, 4:00 AM), https://www.thenational.ae/uae/swiss-search-and-rescue-drone-wins-uaecompetition-1.80836 [perma.cc/48PY-M6VV]; see also FLYABILITY, http://www.flyability.com/ [perma.cc/7RYP-DCVP]

39 See, e.g., Maggie Fox, Feds to Fund Plans to Take on Zika Virus with Drones, NBC NEws (Oct. 12, 2016, 5:36 PM), https://www.nbcnews.com/storyline/zika-virus-outbreak/feds-fund-planstake-zika-virus-drones-n665241 [perma.cc/3ER2-PT4F].

40 See, e.g., April Glaser, Drones Are Being Used by Scientists to Collect Whale Snot, RECODE (June 9, 2017, 10:11 AM), https://www.recode.net/2017/6/9/15765302/drones-scientists-collect-whalesnot-health-pollution-oceans-snotbot [perma.cc/QS58-4JRV].

41 See ZiPLINE, http://www.flyzipline.com/ [perma.cc/K24T-MTVJ]; see also Robert Lee Hotz, In Rwanda, Drones Deliver Medical Supplies to Remote Areas, WALL ST. J. (Dec. 1, 2017, 5:48 AM), https://www.wsj.com/articles/in-rwanda-drones-deliver-medical-suppliesto-remote-areas-1512124200. 
Notwithstanding these wide-ranging activities made possible by micro- and small unmanned airplanes, "[c]ommercial users don't want a drone, they want a solution, a box with a button." 42

Advances in software development-and not necessarily in aerodynamics-explain the accelerating demand for and investment in UAVs in the civil space. A drone is but a piece of hardware-a conventionally "dumb" product that traces its lineage back to the radio-controlled OQ-19 "Dennymite" drone that the U.S. Army used during the 1940s for gunnery practice. 43 The potentially greater value of a drone lies in the system of which a UAV is a part. An unmanned aerial system (a "UAS")44 that pairs a UAV with intelligent flight control, automation, data links, telemetry, communications and navigation equipment, and high-definition cameras offers something more valuable than a remote-controlled airplanenamely, an informational, revenue-generating tool for an ever-expanding range of civil and commercial applications, including agriculture, construction, environment management, GIS (mapping), humanitarian work, oil and gas, cinematography, emergency response, inspection, real estate, and urban surveying. As 3D Robotics' Anderson has noted:

We've focused mostly on drones themselves-the hardware, its cost and capabilities, and what we can attach to it to get work done. But when setting a drone strategy, it's important to think less about drones and

42 Drone Industry REPORT, supra note 2, at 23.

43 William C. Marra \& Sonia K. McNeil, Understanding "The Loop": Regulating the Next Generation of War Machines, 36 HARV. J.L. \& PUB. POL'Y 1139, 1161 (2013).

44 An "Unmanned Aircraft ("UA")" is defined as "[a]n aircraft operated without the possibility of direct human intervention from within or on the aircraft." 14 C.F.R. $§ 107.3$ (2018). A "Small Unmanned Aircraft" is defined as "[a]n unmanned aircraft weighing less than 55 pounds on takeoff, including everything that is onboard or otherwise attached to the aircraft." Id. (emphasis added). "Small Unmanned Aircraft System ("Small UAS")" is defined as "[a] small unmanned aircraft and its associated elements (including communication links and the components that control the small unmanned aircraft) that are required for the safe and efficient operation of the small unmanned aircraft in the national airspace system." Id. 
more about apps. The hardware is primarily an empty vessel to fill with work to be done: taking photographs and video, scanning, moving objects, enabling communication.

And collecting data. Their ability to amass data from a unique, valuable perspective (above, but not too far above), fast and at a low cost makes them ideal collectors. Any drone strategy has to go beyond the drone to the data. And that means moving innovation to the cloud. 45

$$
* * *
$$

Drones will remain primarily data-collection vehicles, but the breadth of apps for them is only just beginning to be discovered ... drones will gain even greater cost advantages when they don't just remove the pilot from the cockpit but remove the pilot entirely. The true breakthrough will come with autonomy. 46

In this context, the core value and competency of many drone companies is as software developers and engineering outfits. For example, Kespry, a California-based drone company, makes UAVs and software for the mining, construction, and insurance industries. 47 AirMap makes a platform for generating maps and alerts for airports, including technology installed on drones to help with preventing aircraft from flying over restricted areas. 48 PrecisionHawk composes software that analyzes data captured from drones used for things like crop analysis in agriculture and pipeline inspections for the energy industry. 49 Airspace makes technology to track and take down rogue drones in flight near, over, or at sports stadiums and major events. 50 In all, UAS fill a "missing middle"-the market

45 Anderson, supra note 4 , at 7.

46 Id. at $5-7$.

47 See The Platform, KESPRY, https://kespry.com/platform/overview [perma.cc/8STL-EUQP].

48 See AIRMAP, https:/www.airmap.com/ [perma.cc/28JL-A4LZ]

49 See PrecisionFlight Pro, PRECISIONHAwK, https:// www.precisionhawk.com/precisionflight-pro [perma.cc/QM3Q-BKZZ]

50 See AIRSPACE, https://airspace.co/ [perma.cc/5KNQ-KD3L]. 
"between satellites and street level, digitizing the planet in high resolution and near-time at a tiny fraction of the cost of alternatives." 51 Thus, software is at the heart of the drone revolution and economy, and is why drone companies, to be successful, are pressed "to provide end-to-end solutions, from hardware, software, and cloud infrastructure (storage and analysis), all the way to client-tailored total solutions." 52

\section{B. Civil UAV Market Segments}

Although drones are traditionally categorized as military or non-military, the civil drone market itself is composed of two segments: a leisure market and a commercial market.53 UAVs in the civil market-that is to say, leisure and commercial UAVs - are often operationally equivalent. Civil drones are defined as fixed-wing aircraft and quadcopters weighing less than 0.55 pounds (approximately 250 grams) and 55 pounds (approximately 25 kilograms), respectively. ${ }^{54}$ As such, the regulatory boundaries between recreational and revenue-generating drones are sometimes blurred. Economic opportunity unifies each market segment, however. According to DJI-Accel SkyFund, for example, investments in drone start-ups occur in six primary areas: "1) robotics and intelligent machines, 2) industrial and vertical applications and cloud services, 3) UAV operations, services, and support, 4) hardware components and battery technology, 5) navigation, obstacle intelligence, and computer vision, and 6) multimedia and video services and communities." 55

Innovations and advances in these areas, in turn, serve three (sometimes overlapping) tiers of civil drone users: (1) leisure, (2) prosumer (e.g., producer-consumer), and (3) commercial.

$51 \mathrm{Id}$. at 5 .

52 Drone Industry REPORT, supra note 2, at 1.

53 See id. at 7. The FAA takes the position that all commercial and model aircraft (also referred to as hobby or recreational aircraft) fall under the heading "civil" aircraft. See also infra Section IV.B.

54 FAA Small Unmanned Aircraft Systems, 14 C.F.R. § 107.3 (2017).

55 Drone Industry RePorT, supra note 2, at 18. 
According to the ConvergEx Group, during the 2014 holiday season, "drone" joined "house," "car," and "stock" as among the top four auto-fill responses on Google to the input, "I want to buy." 56 The consumers keying in these searches constitute the leisure drone segment. More specifically, the leisure drone market refers to amateur and do-it-yourself communities flying remote- and radio-controlled ("RC") airplane models that are small-scale replicas of full-scale aircraft and helicopters. The leisure or microdrone segment "is showing signs of smartphone-like commoditization, where premium specifications are quickly brought down to mass market price points. Manufacturers in this market typically use off-the-shelf components, open-source flight control modules, and third party [original design manufacture]." 57 The central features of hobby or recreational drones is low cost and availability. They range from lightweight, "ready-to-fly," electric-motor, and "toy"-class airplanes up to more substantial airframes with balsa wood or Styrofoam bodies available for purchase off-the-shelf or online from $\$ 20$ to $\$ 700$. Drone manufacturers report extraordinary revenue growth in the toy or hobby market segment of $300 \%$ to $500 \%$ per year. 58

From a regulatory perspective, leisure drones-i.e., drones flown for recreational or hobby purposes exclusively-are referred to as "model aircraft." 59 Their owners and operators

56 See Menchie Mendoza, Drones Rank Fourth on People's Wishlist, TEchTimes (Oct. 4, 2014, 10:21 AM), http://www.techtimes.com/articles/17121/20141004/drones-rank-fourth-onholiday-wishlist-of-people-report.htm [perma.cc/3T4W-76A4] (““[R]eal people' actually wanted to sell their kidney so they could buy a drone. The drone has become a highly recommended product lately, which caused buyers to deviate their attention from purchasing a gun."); see also, e.g., Lauren Pelley, Drone Popularity Soaring this Holiday Season, ToronTo STAR (Dec. 22, 2014), https://www.thestar.com/life/2014/12/22/drone _popularity_soaring_this_holiday_season.html [perma.cc/Z4BA-YH4Q].

57 DRONE INDUSTRY REPORT, supra note 2, at 8.

58 Sarah E. Kreps, Drones: What Everyone Needs To Know 117 (2016).

59 See supra note 53 and accompanying text. 
are essentially self-regulated as a matter of law.60 In fact, aviation enthusiasts have participated in aeromodelling activities, including airplane model competitions and fly-ins, since the dawn of aviation. Unlike full-scale airplane owners and operators, members of the model airplane community conduct themselves not pursuant to federal aviation regulations, but through community-based standards and practices established by the Academy of Model Aeronautics (the "AMA"). 61 According to research findings by ABI Research, toy and hobbyist drone shipments accounted for thirty percent of consumer UAV revenue in 2014, and toy and hobbyist UAV revenue will account for more than two-thirds of the $\$ 4.6$ billion consumer drone market in 2025.62

In contrast to model drones, which in a sense are nothing new or different from remote control toy airplanes dating back to the 1930s, "[p]rosumer drones are the main drivers of civil drone market growth."63 Enabling "laymen to [fly and] take aerial shots previously impossible without expensive gear and [a] professional crew," prosumer drones are "the face of the drone market, combin[ing] features initially unobtainable by the mass market with consumer-friendly user experience but

60 Model aircraft operations must abide by certain rules applicable to all aircraft, including airspace rules, temporary flight restrictions, and 14 C.F.R. § 91.13 (2018), which states that "[n]o person may operate an aircraft in a careless or reckless manner so as to endanger the life or property of another." See also infra Section IV.B.

61 Founded in 1936, the Academy of Model Aeronautics ("AMA") is the world's largest model aviation organization, with a "membership of more than 195,000 from every walk of life, income level and age group." ACADEMY of Model Aeronautics, SAFety Program 25 (2014), http://www.modelaircraft.org/gov/docs/SafetyProgram.pdf [perma.cc/SL5EWDTJ. The Indiana-based organization holds itself out as "the voice of its membership, providing liaison with the FAA, the Federal Communications Commission ('FCC'), and other government agencies . . . AMA also works with local governments, zoning boards, and parks departments to promote the interests of local chartered clubs." Id. at 5 .

62 See Press Release, ABI Research, Consumer Drone Shipments to Exceed 90 Million Units and Generate $\$ 4.6$ Billion in Revenue by 2025 (Jan. 19, 2016), https://www.abiresearch.com/press/consumer-drone-shipmentsexceed-90-million-units-a/ [perma.cc/UG4X-LQ3P].

63 Drone Industry Report, supra note 2 , at 8. 
with premium pricing."64 Referencing a metal cylinder about one inch in diameter and three inches long, Anderson of 3D Robotics explains:

This is a gyro sensor. It is mechanical, it costs $\$ 10,000$, it was made in the nineties by some very talented ladies in an aerospace factory and hand-wound, et cetera. And it takes care of one axis of motion. On our drones we have twenty-four sensors like this. That would have been $\$ 10,000$ each. That would have been $\$ 240,000$ of sensors, and by the way, it would be the size of a refrigerator. Instead, we have a tiny little chip or a few tiny little chips that cost three dollars and are almost invisible. 65

Anderson's point is-as the authors of Machine Platform Crowd: Harnessing Our Digital Future expound-that a Cambrian Explosion of connected devices and sensors on an unmanned aerial platform are possible because of "[t]he combination of cheap raw materials, mass global markets, intense competition, and large manufacturing scale economies."66

But beyond advances in miniaturization and nanotechnology, nothing may be more important to the commercialization and commoditization of drones and the emergence of a prosumer market segment than the smartphone and cloud computing. For example, xCraftwhose principals appeared on ABC's Shark Tank to tout their "phonedrone"-advertises its ability to give "[y]our smartphone access to the third dimension." 67 Anderson, in this spirit, calls personal drones:

64 Id.

65 Andrew McAfee \& Erik Brynjolfsson, When the Automatons Explode: Sever-Less Restaurants. Field-Scanning Drones. When, Where, and How Automation Will Take Hold Next, MIT SloAN Sch. MGMT. (June 30, 2017), http://mitsloan.mit.edu/newsroom/articles/when-the-automatons-explode/ [perma.cc/G8AD-GHHT].

66 Id.

67 PhoneDrone, xCRAFT, http://xcraft.io/phone-drone/ [perma.cc/TV8UG5HQ]. 
[The] peace dividend of the smartphone wars, which is to say that the components in a smartphone-the sensors, the GPS, the camera, the ARM core processors, the wireless, the memory, the batterywhich are driven by the incredible economies of scale and innovation machines at Apple, Google, and others, are available for a few dollars. They were essentially 'unobtainium' ten years ago. Devices that used to be considered military industrial technology can be bought at RadioShack today. 68

In fact,

[u]ntil the late 2000s, activities in the civilian UAV market had the look and feel of the PC market in the late 70 s. It was largely a hobbyist market. There was no universal design, or global conglomerate controlling the market. Products were sold in electronic kit form and in limited quantities, and development of drones was confined to individuals and small, independent groups. Over time, drones have become smaller, cheaper, and easier to operate. 69

The big break in the market occurred in 2010, when French company Parrot released its smartphonecontrolled consumer drone, the 'A.R. Drone.' Shenzhen-based company DJI followed in 2012, releasing its first consumer drone, the "Phantom," with integrated camera and GPS. The two companies have since dominated the consumer market, each to date has shipped over one million drones. 70

In 2015, the pace of new firms entering the drone market accelerated. Venture capital investments in UAV manufacturers and UAV application developers more than tripled over 2014. Today, applications for UAVs continue to grow with increasingly sophisticated functionality and a wider range of market segments. As component prices continue to fall

68 McAfee \& Brynjolfsson, supra note 65.

69 Drone Industry REPORT, supra note 2, at 5.

70 Id. 
and open-source flight control software improves in stability and reliability, some analysts expect more low-cost consumer drone makers will emerge from China; it seems only a matter of time before consumer drones are as commoditized as Android smartphones. 71

In this context, the prosumer market "is going through the most rapid pace of innovation [with] new technologies in machine vision, image processing, range sensors, and robotics (autonomous control systems)." 72 The primary operators in the prosumer market are aspirational and professional photographers, served by nearly 450 manufacturers from around the world.73 DJI, 3D Robotics, SenseFly, Yuneec, and Trimble are the top five most penetrated UAV makers among commercial UAV operators in the United States, with Shenzhen-based DJI penetrating almost eighty-five percent of the entire market.74

Finally, separate from the prosumer drone marketthough not entirely independent-is the professional segment. Like the prosumer market, at the center of the commercial or professional drone market are devices with automated and aerial image and/or data collection capabilities. For example, in professional filmmaking and television, the FAA has granted exemptions allowing the flight of tethered drones over people in closed set operations. And, as recently as October 2017, CNN obtained a first-of-itskind commercial drone operating license from the FAA for operation of the Vantage Robotics Snap drone over open-air crowds of people at altitudes up to 150 feet. 75 Similarly, ESPN

71 Id.

$72 I d$. at 9 .

73 See List All Manufacturers, UAVGLOBAL, http://www.uavglobal.com/list-of-manufacturers/ [perma.cc/5YLG-FN4B].

74 Drone Industry RePORT, supra note 2, at 13.

75 Press Release, CNN Receives Breakthrough Part 107 Waiver for Operations over People (Oct. 18, 2017), http://cnnpressroom.blogs.cnn.com/2017/10/18/cnn-receives-breakthroughpart-107-waiver-for-operations-over-people/ [perma.cc/2XJD-S42L]. 
filmed the Winter $\mathrm{X}$ games with a drone, 76 coinciding with the emergence of drone racing as an increasingly popular sport that merges Formula 1 racing with video-gaming. In fact, the Drone Racing League, Inc. recently raised twenty million dollars in Series B funding77 in addition to early investments from venture capitalists backed by Miami Dolphins owner and RSE Ventures Founder, Stephen Ross.78

Beyond media and entertainment, analysts posit that infrastructure inspection, agriculture, construction, insurance, telecommunication, and logistics are the likeliest niche markets to benefit from commercial drones. The first commercial drone flew over U.S. land in 2013, after the FAA authorized BP energy and California-based manufacturer AeroVironment's request to fly the Puma AE UAV at BP's Prudhoe Bay oilfield located on Alaska's North Slope. 79

76 See Sean O'Kane, ESPN is Filming the Winter X-Games with a Drone, VERGE (Jan. 21, 2016, 6:20 PM), https://www.theverge.com/2015/1/21/7868825/espn-winter-x-games-drone [perma.cc/W66T-M2ZX].

77 See Fitz Tepper, Drone Racing League Raises a \$20M Series B Ahead of Its 2nd Season, TECHCRUNCH (June 12, 2017), https://techcrunch.com/2017/06/12/drone-racing-league-raises-a-20mseries-b-ahead-of-its-2nd-season/ [perma.cc/K2MK-C8PW].

78 See Emily Nonko, Developer Stephen Ross's RSE Ventures Invests in Drone Racing, WALL ST. J. (Aug. 12, 2015), https://www.wsj.com/articles/developer-stephen-rosss-rse-ventures-investsin-drone-racing-1439327632; see also Ian Frazier, The Trippy High-Speed World of Drone Racing, NEw Yorker (Feb. 5, 2018), https://www.newyorker.com/magazine/2018/02/05/the-trippy-high-speedworld-of-drone-racing.

79 See Press Release, Fed. Aviation Admin., FAA Opens the Arctic to Commercial Small Unmanned Aircraft (Sept. 23, 2014), https://www.faa.gov/news/updates/?newsId=73981 [perma.cc/7FSA-S8LL]; see also Zaz Hollander, Drone at Prudhoe Bay Makes First FAA-Authorized Unmanned Commercial Flight Over Land, ANCHORAGE DaILY News, http://www.adn.com/article/20140610/drone-prudhoe-bay-makes-first-faaauthorized-unmanned-commercial-flight-over-land-0 [perma.cc/7QQ8DHFX] (last updated Sept. 28, 2016) ("The Puma AE, manufactured by California-based AeroVironment, will buzz over the North Slope courtesy of a five-year contract with BP. The energy giant paid an undisclosed amount for the unmanned aircraft, with plans to use it to survey more than 200 
Autodesk and Komatsu have invested in Skycatch to enable real-time analysis of the progress on construction site projects for its clients, including Clayco, Bechtel, and Chevron.80 And, in partnership with Airware, General Electric uses drones to inspect power lines. Altogether, "[a]ny business managing acres, hectares, or other large spaces can immediately decrease time and labor costs by using drones to blanket those areas, whether for testing, surveying, mapping, inspecting, or counting trees or boats." 81

Of these verticals, however, 'precision agriculture' is perhaps the most significant existing application of commercial drones. Though precision agriculture is a new phenomenon in the United States, farmers have used drones for pesticide spraying purposes in Japan since the 1980s, and Yamaha has operated small, remotely piloted helicopters for commercial purposes since 1991. 82 Now, using high resolution, multispectral, thermal, and hyperspectral sensors on drones, the business case for agriculture drones is even stronger as farmers can use UAVs to estimate acreage, assess yield, monitor soil conditions, and survey crop health from the air-a data-driven approach that is far more efficient and cost-effective than manual, ground-based processes reliant on the naked eye. A Harvard Business Review case study made the point: Juxtaposing the survey of a 7.5-hectare construction site by conventional means and by a drone, two people needed 11.5 hours to survey the site while one person needed just fifty minutes using a drone. 83

Advances in precision agriculture aside, the reach and efficiency of drones may be most exciting in terms of Internet service and package delivery. Facebook, for example, has experimented with a solar-powered, high-altitude drone-

miles of gravel road, well pads, a gravel pit and the 1,300 miles of pipelines at Prudhoe Bay.").

80 Drone Industry RePort, supra note 2, at 12.

81 Berinato, supra note 9, at 16.

82 See Yamaha Remotely Piloted Helicopters, YamaHa Motor CoRP., https://www.yamahamotorsports.com/motorsports/pages/precisionagriculture [perma.cc/PT8Z-SXR6].

83 Anderson, supra note 4, at 13. 
Aquila-that stays aloft for up to ninety days, offering Internet access to an area sixty miles wide. 84

DHL, 85 Alibaba, 86 Amazon, 87 and Walmart, 88 meanwhile, are investigating ways to use UAVs to deliver goods via drone. According to a KPMG report, "[b]y 2019, the commercial small unmanned aerial systems (UAS) sector would have revenue of more than US $\$ 5.1$ billion-five times the revenue of the consumer drone market and more than twice the revenues of the combined military and civil market currently dominating the industry." 89

Notwithstanding substantial investment and investors in the civil drone market, whether anyone is making money in the drone economy-and if so, how much-remains an open question. Many drone makers are startups, and are thus private companies for which financial data is not publicly

84 Darrell Etherington, Facebook's Aquila Drone Completes its Second Test Flight, Lands Well This Time, TEchCRUCH (June 29, 2017), https://techcrunch.com/2017/06/29/facebooks-aquila-drone-completes-itsecond-testflight-lands-well-this-time/ [perma.cc/82PL-HPPX]. But see Brian Heater, As UAV Internet Proves Too Complex, Alphabet Shifts the Titan Team to Projects Loon and Wing, TechCRUnch (Jan. 11, 2017), https://techcrunch.com/2017/01/11/google-titan/ [perma.cc/TYV3-FGWR].

85 See e.g., Michael Franco, DHL Uses Completely Autonomous System to Deliver Consumer Goods by Drone, New AtLAs (May 10, 2016), https://newatlas.com/dhl-drone-delivery/43248/ [perma.cc/N7GM-EM9H].

86 See e.g., Yang Yi, Chinese e-Commerce Giant Alibaba's Drones Deliver Packages to Islands, XinhUANet (Nov. 8, 2017, 8:05 AM), http://news.xinhuanet.com/english/2017-11/08/c_136735278.htm [perma.cc/9C9G-RT9U].

87 See, e.g., Fahad Manjoo, Think Amazon's Drone Delivery Idea is a Gimmick? Think Again, N.Y. TIMES (Aug. 10, 2016), https://www.nytimes.com/2016/08/11/technology/think-amazons-dronedelivery-idea-is-a-gimmick-think-again.html.

88 See e.g., Jonathan Vanian, Drones May One Day Buzz Inside a Walmart Near You, ForTune (Mar. 17, 2017), http://fortune.com/2017/03/17/walmart-drone-delivery-patent/ [perma.cc/WF7X-2YQM].

89 Next Tech: Drones Set to Take Off, KPMG (Nov. 8, 2016), https://home.kpmg.com/be/en/home/insights/2016/11/next-tech-drones-setto-take-off.html [perma.cc/K2K4-54G2] (quoting an ABI Research report). 
available. 90 Additionally, in the prosumer drone market, one company-DJI-dominates the market across all price ranges above $\$ 500$ to such an extent that the second-place firm in the $\$ 500-\$ 1,000$ price range for UAVs-3D Robotics, which had had nineteen percent of the market-stopped making drones altogether in 2016, shifting to a software focus. 91

Other drone manufacturers are also having trouble keeping up. For example, France-based Parrot and China's Yuneec (both of which captured seven percent of the market in the $\$ 500-\$ 1,000$ price range) laid off employees in 2016.92 Lily, a startup maker of inexpensive consumer camera drones, ceased business without ever shipping a single drone after raising millions of dollars' worth of preorders.93 Meanwhile, GoPro recalled its "Karma" drone only weeks after it was launched, following reports of malfunctions that caused it to lose power and fall from the sky; the Karma went on to become the second-best-selling drone in the United States by late 2017 only to be discontinued due to "[a] hostile regulatory environment in Europe and the United States."94 In the final analysis, notwithstanding the "bullish view that UAVs are an essential layer in the 'trillion sensor' world, and in the age of

90 See Divya Joshi, Commercial Unmanned Aerial Vehicle (UAV) Market Analysis-Industry Trends, Companies and What You Should Know, Bus. INSIDER (Aug. 8, 2017, 6:02 PM), http://www.businessinsider.com/commercial-uav-market-analysis-2017-8 [perma.cc/P829-WV4G].

91 April Glaser, DJI Is Running Away with the Drone Market, RECODE (Apr. 14, 2017, 3:34 PM), https://www.recode.net/2017/4/14/14690576/ drone-market-share-growth-charts-dji-forecast [perma.cc/63QT-R5LV].

92 Id.

93 April Glaser, What Happened to the Lily Camera Drone?, RECoDE (Jan. 16, 2017, 2:40 PM), https://www.recode.net/2017/1/16/14274254/lilydrone-lawsuit-refunds [perma.cc/MA3G-CGRV].

94 Imani Moise \& Chelsey Dulaney, GoPro to Cut 20\% of Workforce, Exit Drone Market, WALL ST. J. (Jan. 8, 2018, 8:16 PM), https://www.wsj.com/articles/gopro-to-cut-20-of-its-workforce-exit-dronemarket-1515426190 ("GoPro also said . . . it will stop selling drones after clearing its existing inventory, attributing the decision to regulatory uncertainty. 'A hostile regulatory environment in Europe and the United States will likely reduce the total addressable market in the years ahead,' the company said.”). 
IoT, plenty of regulatory, technological, and social barriers still exist before their wider adoption."95

\section{Business Ethics and Regulatory Ambiguity}

In March 2017, the FAA established the Regulatory Consistency Communication Board to provide guidance and clarification to business aviation operators by clarifying inconsistencies related to the application of regulations.96 The establishment of a similar body would have been an immense help to startup drone firms almost a decade ago when initial FAA positions-along with the absence of any clearly controlling regulations or formal rulemaking — created great uncertainty in the business community. The FAA's efforts to manage civil drone operators exemplified how an administrative agency can potentially derail a transformative innovation-and invite ethically ambiguous business behavior-in the process of effecting its regulatory mission.

For example, the FAA actively litigated the definition of drone itself (as opposed to "model aircraft"). 97 This was curious because, as detailed in Section II.B supra, drones in the leisure, prosumer, and commercial drone segments overlap substantially as a practical matter. Yet, regulators have imagined consequential - though seemingly arbitrarylegal distinctions based on the operation of a drone. What is the difference between a model airplane flown strictly for hobby purposes and a drone flown by a logistics company to deliver goods? Practically, the answer can be nothing. But for regulators, the answer has been essentially everything. A coherent answer to this question did not present officially for almost a decade, creating ethical dilemmas as some commercial UAV operators and legal professionals took

95 Drone Industry REPORT, supra note 2, at 9.

96 See, e.g., New FAA Review Board Offers Clarity on Inconsistent Interpretations of Regulations, NAT'L Bus. AviATION Ass'N (Mar. 29, 2017), https://www.nbaa.org/ops/20170329-new-faa-review-board-offers-clarityon-inconsistent-interpretations-of-regulations.php [perma.cc/LPH9QMNR].

97 See infra Section IV.B. 
advantage of regulatory uncertainty while conservative commercial UAV firms, led by cautious legal counsel, 98 remained grounded waiting hopefully for permission to fly.

98 Drone lawyers are a business story unto themselves. See e.g., Monika Gonzalez Mesa, Drone Law Practices Taking Off-Again, Daily Bus. Rev. $\begin{array}{llll}\text { (May 8, 2017, } & \text { 1:00 }\end{array}$ https://www.law.com/dailybusinessreview/almID/1202785548836 [perma.cc/F3ZD-MRUA]; Darlene Ricker, Navigating Drone Laws Has Become a Growing and Lucrative Legal Niche, ABA J. (July 2017), http://www.abajournal.com/magazine/article/drone_law_attorneys [perma.cc/WL8P-N35P]; Victor Li, Firms Bet on Growth Potential of Drone Law, ABA J. (Oct. 27, 2014, 10:08 AM), http://www.abajournal.com/lawscribbler/article/look_up_in_the_firm_its_d rone_law/ [perma.cc/5555-ZBRJ]. Given that the FAA only enacted drone specific regulations in 2016, the idea that any expertise has existed or yet fully exists in a new and inherently cross-disciplinary subject matter known as "drone law" may be overstated. In a related context, Judge Frank Easterbrook, in the context of cyberlaw, rejected the idea that the study of law as applied to common objects can stand alone:

[T] he best way to learn the law applicable to specialized endeavors is to study general rules. Lots of cases deal with sales of horses; others deal with people kicked by horses; still more deal with the licensing and racing of horses, or with the care veterinarians give to horses, or with prizes at horse shows. Any effort to collect these strands into a course on "The Law of the Horse" is doomed to be shallow and to miss unifying principles. Teaching 100 percent of the cases on people kicked by horses will not convey the law of torts very well. Far better for most students-better, even, for those who plan to go into the horse trade-to take courses in property, torts, commercial transactions, and the like, adding to the diet of horse cases a smattering of transactions in cucumbers, cats, coal, and cribs. Only by putting the law of the horse in the context of broader rules about commercial endeavors could one really understand the law about horses.

Frank H. Easterbrook, Cyberspace and the Law of the Horse, 1996 UNIV. CHI. LEGAL F. 207, 207-08 (1996). In this context, the idea of legal expertise about a specific technology connected to the IoT raises interesting ethical issues of what claims lawyers can or should make in attracting clients and whether negative recruiting is appropriate or consistent with state bar rules. See, e.g., Gary Mortimer, Drone Lawyers and Kickbacks, sUAS NEws (May 3, 2016), https://www.suasnews.com/2016/05/drone-lawyer-kickbacks/ [perma.cc/4CVD-ALKR] ("Come on FAA get on with it, you are creating a 
While the FAA does not regulate model aircraft operations, 99 hobby and recreational model aircraft owners and operators have been served for the last three decades by an FAA guidance document designed to promote "a good neighbor environment with affected communities and airspace users."100 More specifically, in 1981, the FAA published Advisory Circular ("AC") 91-57, entitled "Model Aircraft Operating Standards."101 It recommended where model aircraft operators should fly their remote controlled airplanes, including below 400 feet, three miles of an airport, and away from populated areas.102 AC 91-57 further suggested that hobby-type airplane operators maintain a sufficient distance away from populated and noise-sensitive areas such as parks, schools, hospitals, and churches. 103 Additionally, the FAA suggested that hobbyists and recreational flyers avoid operations near spectators until the model aircraft being flown had been flight tested and proven airworthy. 104 Finally, the FAA expected hobbyists not to operate BVLOS, giving way to, and avoiding, full-scale aircraft. 105

market for folks to be hoodwinked."); Other Drone Services, RUPPERCHT LAW, https://jrupprechtlaw.com/other-drone-services [perma.cc/TY64-WNK3] ("So when choosing professionals to help you, don't hire a poser-hire a pilot. Why? Aviation posers will keep your operations grounded while commercial pilots will help it soar.").

99 This should not be read to mean that no federal aviation regulations apply to model aircraft- they do in specific and limited circumstances. See, e.g., 14 C.F.R. pt. 48 (2017) (governing registration and marking requirements for small unmanned aircraft).

100 Fed. Aviation Admin., U.S. Dep't of Transp., Advisory Circular No. 91-57, Model AirCRAFt OPERATING STANDARDS 11 (1981).

$101 \mathrm{Id}$.

$102 I d$. at 9 3(a), (c).

103 Id.

104 Id. at $93(\mathrm{~b})$.

105 Id. at $9(\mathrm{~d})$. 
Significantly, AC 91-57 is advisory, not mandatory.106 It only encouraged "voluntary compliance."107 Thirty-five years after its issuance, as drones became popular, AC 91-57 thus presented misunderstanding - and opportunity. Assertive (or unscrupulous) UAV operators looking to turn a profit took to the skies on the basis that AC 91-57 allowed commercial UAV flights in the absence of any law, regulation, or policy to the contrary or any law governing drones explicitly. The FAA reacted by issuing a notice in February 2007 intended to clarify that AC 91-57 only applied to modelers:

The FAA recognizes that people and companies other than modelers might be flying UAS with the mistaken understanding that they are legally operating under the authority of AC 91-57. AC 91-57 only applies to modelers, and thus specifically excludes its use by persons or companies for business purposes. 108

As such, the FAA ostensibly brought commercial drones within its ambit, justifying its authority in terms of its mission "to provide the safest, most efficient aerospace system in the

106 The FAA updated AC 91-57 in September 2015 with the issuance of AC 91-57A. See Fed. Aviation Admin., U.S. DeP’t of Transp., Advisory Circular No. 91-57A, Model Aircraft Operating Standards $\mid 1$ (2015). Like its predecessor advisory, the new policy states that "aero-modelers generally are concerned about safety and exercise good judgment when flying model aircraft for the hobby and recreational purposes for which they are intended, [and] they may share the airspace in which manned aircraft are operating." However, the advisory now specifically references UAVs, providing that "[u]nmanned aircraft, including model aircraft, may pose a hazard to manned aircraft in flight and to persons and property on the surface if not operated safely." Thus, the FAA has retained the authority to prosecute unscrupulous or careless operators: "Model aircraft operations that endanger the safety of the National Airspace System, particularly careless or reckless operations or those that interfere with or fail to give way to any manned aircraft may be subject to FAA enforcement action." Enforcement action, then, hinges upon which regime the aircraft is operating within, i.e., as a recreational model aircraft or a Part 107 small UAS operation. Id.

107 Fed. Aviation Admin., supra note 101, at 1 (emphasis added).

108 Unmanned Aircraft Operations in the National Airspace System, 72 Fed. Reg. 6689 (Feb. 13, 2007). 
world."109 Indeed, UAVs posed unique hazards to manned and unmanned assets in the navigable airspace over which the FAA has jurisdiction. First-person view ("FPV") capabilities that allow an operator to fly a drone BVLOS using a video stream raise safety concerns about collisions not traditionally associated with, for example, remote control model airplanes.

The FAA's safety mission did not explain why the FAA strictly forbade commercial drones, however. First, on its own terms, it was not obvious that AC 91-57 applied to drones. Second, the FAA did not amend or modify its policy or extend rules originally intended for the model aviation community to modern UAVs. Third, the FAA did not promulgate any standalone regulations with respect to civil drones (and it did not do so until August 2016), which it has the authority and competence to do. Finally, the FAA's 2007 policy clarification was not the product of any formal rulemaking process, but only guidance supposedly clarifying a thirty-five year-old document that did not envision, and perhaps could not have envisioned, "smart" model aircraft with commercial applications. Most frustrating for commercial UAV operators, however, was the FAA's unexplained and arbitrary policy allowing drones to fly for fun but not for business - even if the same device was used. 110

The FAA's legal position respecting commercial drones did not address the reality that no differences whatsoever might

109 FED. AVIATION ADMIN., Mission and Responsibilities, https:/www.faa.gov/airports/central/about_airports/CE_mission/ [perma.cc/439B-PCWZ] (last updated Aug. 21, 2014, 6:12 PM).

110 The FAA has applied an accepted dictionary definition of recreation, defining hobby" as a "pursuit outside one's regular occupation engaged in especially for relaxation" and recreation as "a refreshment of strength and spirits after work; a means of refreshment or diversion." See Interpretation of the Special Rule for Model Aircraft, 79 Fed. Reg. 36171 (June 25, 2014), https://www.faa.gov/uas/media/model_aircraft_spec_rule.pdf [perma.cc/3HL6-JSY3]. The FAA has opined that any operation not conducted strictly for hobby or recreation purposes would fall outside the special rule for model aircraft; and, clearly, commercial operations would not be hobby or recreation flights in this context. $I d$. Likewise, the flight of a model airplane in furtherance of a business, or incidental to a person's business, would not be a hobby or recreation flight. Id. 
exist between a drone flown by an amateur hobbyist and a drone flown by a UPS employee to deliver packages. Leisure, prosumer, and commercial drone owners and operators can and do use the exact same machine and equipment capable of flight BVLOS. Indeed, what is interesting and compelling about the drone economy is the commodification of aviationthe availability of professional grade aerial platforms (with or without action cameras) to the general consumer. The line between model aircraft and drones is "increasingly arbitrary as drones have become smaller and hobbyist model aircraft have become more sophisticated."111 Thus, while the FAA's concern about and jurisdiction over the safety of UAV flying BVLOS was well founded, or at least arguable, its different treatment of "model" aircraft and commercial dronesseemingly on the basis of nothing more than whether or not the flight was conducted for business purposes-was inexplicable. Yet, six years after issuing its "clarification" in $2007,{ }^{112}$ the FAA maintained its per se ban on commercial UAVs without also producing any rules or a pathway forward for commercial UAVs.

In 2012, Congress addressed frustration with the FAA and the pent-up demand for commercial drone operations by enacting the FAA Modernization and Reform Act of 2012 (the "FMRA"), 113 pursuant to which Congress directed the FAA to produce a comprehensive set of regulations to "safely accelerate the integration of civil unmanned aircraft systems into the national airspace system." 114 Importantly, Congress explicitly carved out an exception in section 336 of the FMRA for "model aircraft . . . flown strictly for hobby or recreational

111 KREPS, supra note 58, at 8.

112 Unmanned Aircraft Operations in the National Airspace System, 72 Fed. Reg. 6689 (Feb. 13, 2007).

113 FAA Modernization and Reform Act of 2012, H.R. Rep. No. 112-381 (2012), https://www.gpo.gov/fdsys/pkg/CRPT-112hrpt381/pdf/CRPT112hrpt381.pdf [perma.cc/MG95-SD55].

114 See, e.g., FAA Modernization and Reform Act of 2012, Pub. L. 11295, § 332(a)(1), 126 Stat. 11 (2012). 
use."115 In its Interpretation of the Special Rule for Model Aircraft dated June 18, 2014, the FAA acknowledged that section 336 of the FMRA disallowed it from promulgating "any rule or regulation regarding a model aircraft, or an aircraft being developed as a model aircraft."116 But again, the FAA maintained its approach that the flight of a drone for fun and the flight of that very same drone for a business purpose required different regulatory treatment. To illustrate its position, the FAA published a table giving examples of allowable hobby flying versus non-recreational flying that required special permission. 117

115 Operation and Certification of Small Unmanned Aircraft Systems, 81 Fed. Reg. 42064, 42080 (June 28, 2016) (to be codified at 14 C.F.R. pts. $21,43,61,91,101,107,119,133,183)$.

116 The FAA has interpreted the prohibition against it under section 336 as one that must be evaluated on a rule-by-rule basis. See FED. AviATION Admin., DeP'T of Transp., Docket No. FAA-2014-0396, InTERPRETATION OF THE SPECIAL RUlE FOR MODEL AIRCRAFT 7-8, https://www.faa.gov/uas/media/model_aircraft_spec_rule.pdf [perma.cc/W4N4-3AEN]; FAA Modernization and Reform Act of 2012, Pub. L. 112-95, § 336(c)(1), 126 Stat. 11 (2012) (defining "model aircraft" as "an unmanned aircraft that is capable of sustained flight in the atmosphere; flown within visual line of sight of the person operating the aircraft; and flown for hobby or recreational purposes").

117 See also Fed. Aviation Admin., supra note 116, at 11 fig. 1. 
Figure 1. AlLOWABLE VERSUS DisALLOWED UAV FLIGHT

\begin{tabular}{|l|l|}
\hline Hobby or Recreation & Not Hobby or Recreation \\
\hline $\begin{array}{l}\text { Flying a model aircraft } \\
\text { at the local model } \\
\text { aircraft club. }\end{array}$ & $\begin{array}{l}\text { Receiving money for } \\
\text { demonstrating } \\
\text { aerobatics with a model } \\
\text { aircraft. }\end{array}$ \\
\hline $\begin{array}{l}\text { Taking photographs } \\
\text { with a model aircraft } \\
\text { for personal use. }\end{array}$ & $\begin{array}{l}\text { A realtor using a model } \\
\text { aircraft to photograph property } \\
\text { that he is trying } \\
\text { to sell and using the photos in } \\
\text { the property's real estate } \\
\text { listing. } \\
\text { A person photographing a } \\
\text { property or event and selling } \\
\text { the photos to someone else. }\end{array}$ \\
\hline $\begin{array}{l}\text { Using a model aircraft to } \\
\text { move a box from point to } \\
\text { kind without any }\end{array}$ & $\begin{array}{l}\text { Delivering packages to people } \\
\text { for a fee. }\end{array}$ \\
\hline $\begin{array}{l}\text { Viewing a field to determine } \\
\text { whether crops need } \\
\text { water when they are grown } \\
\text { for personal enjoyment. }\end{array}$ & $\begin{array}{l}\text { Determining whether crops } \\
\text { need to be watered that are } \\
\text { grown as part of } \\
\text { commercial farming } \\
\text { operations. }\end{array}$ \\
\hline
\end{tabular}

The fact that a model aircraft used "to move a box from point to point without any kind or compensation" warranted different regulatory treatment than a UAV used to "[d]eliver[ packages to people for a fee" unnecessarily targets commercial operations. 118 And ironically, for the better part of a decade, the FAA imposed stringent permitting requirements on would-be commercial UAV operators-operators who, in 
many instances, had a business interest in operating safelywhile leaving amateurs with little to lose other than their nominal investment in an over-the-counter toy.

And so the resulting regulatory environment has been aptly described as the "Wild West." 119 Opportunistic drone operators multiplied and gained market share by virtue of a debatable reading of AC 91-57 and the concomitant absence of drone regulations at the expense of risk-averse UAV operators who waited for definite regulatory approval to do business. In 2014, for example, Fly Boys Aerials incorrectly announced on its website that, "[f]or the moment, commercial drones, are, unequivocally, legal."120 Meanwhile, other UAV operators announced how easy it was to fly cinema cameras on drones: "All we need is a location with a large open unobstructed area, such as a sound stage, warehouse, sports facility, auditorium, etc."121 The website for New York's SkyCamUSA published an "FAA Compliance Statement" (replicated below) designed to reassure potential customers about the commercial applications of its drones:

\section{General Overview}

The term drone in the media tends to give people a certain image or idea of what a drone is. Actually drones come in many forms and serve many purposes most of them friendly. The "drones" we operate are friendly drones. Our drones are short range with about 5-10 min flight time. The only act besides flying

119 Kevin C. Desouza et al., Drones and the "Wild West" of Regulatory Experimentation, BRoOKINGS: TECHTANK (Aug. 17, 2015), https://www.brookings.edu/blog/techtank/2015/08/17/drones-and-the-wildwest-of-regulatory-experimentation/ [perma.cc/RX95-87U3] ("The challenge this rapidly developing technology is creating is well ahead of local government efforts to rein in excessive activities. State and local governments need to engage on this policy issue more proactively.").

120 Jason Kobeler, Commercial Drones Are Completely Legal, a Federal Judge Ruled, Fly Boys Aerial Cinematography (Mar. 6, 2014, 6:51 PM), http://flyboysair.com/2014/03/11/commercial-drones-now-legal/ [perma.cc/CTA4-67US] (emphasis added).

121 Frequently Asked Questions, TCB Productions, https://www.tcbproductions.net/portfolio [perma.cc/UKS4-87U8]. 
they are capable of is professional aerial photography and video. They do not drop anything. Their usage is strictly used in a manner productive to respecting the privacy and rights of others. ...

We do not photograph any persons [sic] property or person in a selective way without authorization of the client.... Our aerial vehicles are used for good and evolutionary purposes only and in places that are safe. ...

\section{Additional Information}

The remote controlled aircraft that we use sometimes referred to as a drone is a low altitude, close range, open space hobby flyer and flown only in a safe area and does not operate near any airports, aircraft or violate any FAA regulations. The remote controlled helicopter is NOT a Drone or UAV or autonomous in anyway [sic] and is flown by hand only within visual line of sight of the operator always in a safe location and never near any airport or aircraft. . . 122

This early statement was made up; the FAA had not authored or sanctioned any such compliance statement. These and other commercial UAV activities were not necessarily illegal or unethical. However, as one observer put it: "The horse has left the stable. Now is not the time [for the FAA] to bolt the barn and stand guard over an empty stall." 123

While the FAA's hard, rule-less stance relating to commercial drones created legal and practical ambiguity, several organizations interested in operating drones took the long view by working with regulators to secure permission to

\footnotetext{
122 FAA Compliance Statement, SkyCAMUsA, https://web.archive.org/web/20160117095311/http://www.skycamusa.com:8 0/legal.shtml (statement available on Jan. 17, 2016). SkyCamUsa's statement has been repeatedly revised in light of FAA activity involving UAVs. For the most recent version, see FAA Compliance Statement, SKYCAMUsA, http://www.skycamusa.com/legal.shtml [perma.cc/G9HM$2 \mathrm{C} 2 \mathrm{H}]$.

123 Speed and Transparency Needed for Civil UAS Use, 176 Aviation WK. \& SpACE TECH., May 26/June 2, 2014, at 74.
} 
fly. The Motion Picture Association of America (the "MPAA"), for example, was among the first organizations to emphasize the tangible economic benefits of UAVs in the film industry and urged the FAA to make an exception to allow filmmakers to fly in the national airspace. 124 Given existing aerialphotography expertise in the industry, coupled with the fact that film sets are usually closed environments, the FAA was open to accommodating the MPAA. 125 As such, the FAA proceeded on a case-by-case basis-a progressive step, but one that left the industry fragmented operationally:

Every time a filmmaker wants to shoot in the United States using a drone, they have to ink a one-time deal with the authorities for permission. In other countries where the rules are more lax, the checks may be weaker or nonexistent. And that's led to an explosion in the international market for unmanned aerial footage. 126

For operators outside the MPAA, obtaining permission from the FAA seemed draconian. For instance, journalism programs at the University of Missouri, the University of Nebraska, and the Tow Center for Digital Journalism at

124 See Brendan Sasso, Hollywood Wants Drones for Filmmaking, THE HILL (Jan. 25, 2013, 11:00 AM) http://thehill.com/policy/technology/279235hollywood-wants-drones-for-movie-making [perma.cc/4D8U-CV2U].

125 See, e.g., Alex Brown, Hollywood Producers Want to Use Drones to Film Their Movies, NAT'L J.: TECH. (June 2, 2014, 1:02 PM) http://www.nationaljournal.com/tech/hollywood-producers-want-to-usedrones-to-film-their-movies-20140602. In 2014, the FAA granted regulatory exemptions to six aerial photo and video production companies-Astraeus Aerial, Aerial MOB, LLC, HeliVideo Productions, LLC, Pictorvision Inc, RC Pro Productions Consulting, LLC dba Vortex Aerial, and Snaproll Media, LLC - "the first step to allowing the film and television industry the use of unmanned aircraft systems (UAS) in the National Airspace System." Press Release, Fed. Aviation Admin., U.S. Transportation Secretary Fox Announces FAA Exemptions for Commercial UAS Movie and TV Production (Sept. 25, 2014), http://www.faa.gov/news/press_releases/ news_story.cfm?cid=TW251\&newsId=17194 [perma.cc/52HF-DF6Z].

126 See Brian Fung, It's a Bird! It's a Plane! It's a Drone that Makes Movies!, WAsH. Post (Aug. 15, 2013), https://www.washingtonpost.com/news/the-switch/wp/2013/08/15/its-abird-its-a-plane-its-a-drone-that-makes-movies/. 
Columbia University launched drone journalism courses. 127 However, such programs were chilled when, for example, the FAA grounded students in the Missouri program who flew a UAV over a prairie for a story without first obtaining agency permission in advance. 128

In all, the FAA's ex-ante, one-size-fits-all ban on commercial drones was ineffective and sometimes flouted. An editorial in Aviation Week and Space Technology noted:

[T] he agency's interaction with a frustrated civil UAS community is limited to wagging a finger at unsafe operations, slapping cease-and-desist orders on "illegal" operators and fines on reckless fliers, and defending those bans and fines against legal challenges. All the while, the FAA hides in the labyrinth of rulemaking when asked important questions. 129

This set of circumstances lasted for approximately nine years, after which the FAA codified the first set of uniform, national drone regulations that broadly permitted civil UAV operations with certain exceptional operations to be allowed on a case-by-case waiver basis-e.g., night operations, BVLOS, operations over people. And as such, the initial approach that regulators took with respect to commercial drones for almost a decade-namely, ex-ante prohibitions and ex-post allowances-impeded the development of a commercial UAV market and turned out to be the exact opposite of the regulatory framework that regulators ultimately would establish. Indeed, current civil UAV

127 See Alex Davies, The FAA Has Shut Down 2 Journalism School Drone Programs, Bus. Insider (Aug. 23, 2013, 5:48 PM), http://www.businessinsider.com/faa-ends-journalism-school-drone-use2013-8; see also Leslie Kaufman \& Ravi Somaiya, Drones Offer Journalists a Wider View, N.Y. Times (Nov. 24, 2013), http://www.nytimes.com/2013/11/25/business/media/drones-offerjournalists-a-wider-view.html.

128 See Kaufman \& Somaiya, supra note 127.

129 Speed and Transparency Needed for Civil UAS Use, supra note 123, at 74 . 
regulations (i.e., Part 107130) establish ex-ante allowances subject to ex-post enforcement-a scheme that would have worked many years ago.

The remainder of this Article will focus on the specific challenges that aviation regulators have had and are having with respect to innovations in unmanned aviation. This analysis may apply generally to the ways in which authorities should think about emerging technologies in the IoT.131

\section{THE UAV LEGAL ENVIRONMENT}

The June 10, 1956 edition of the Van Nuys (Calif.) News said that the three most important things about real estate are location, location, location. 132 Nowhere is this business precept more important-from a legal point of view-than in the context of commercial drones. As detailed in Stuart Banner's Who Owns the Sky: The Struggle to Control Airspace from the Wright Brothers On,133 since approximately the midto late 1800s, manned aviation has disrupted the Roman concept that one who owns land also owns the skies above

130 Small Unmanned Aircraft Systems, 14 C.F.R. pt. 107 (2018).

131 In future work, the author intends to consider the possibility that regulation is virtually unnecessary in this area of law and that insurance requirements or tort law can control the safety issues.

132 See e.g., William Safire, Location, Location, Location, N.Y. TIMES MAG. (June 26, 2009), http://www.nytimes.com/2009/06/28/magazine/28FOB-onlanguage-t.html.

133 See Stuart Banner, Who Owns the Sky? The Struggle to Control Airspace from the Wright Brothers ON 23 (2008); see also United States v. Causby, 328 U.S. 256, 260-61 (1946) ("It is ancient doctrine that at common law ownership of the land extended to the periphery of the universe-Cujus est solum ejus est usque ad coelum. But that doctrine has no place in the modern world. The air is a public highway, as Congress has declared. Were that not true, every transcontinental flight would subject the operator to countless trespass suits. Common sense revolts at the idea. To recognize such private claims to the airspace would clog these highways, seriously interfere with their control and development in the public interest, and transfer into private ownership that to which only the public has a just claim.”). 
it.134 Laws established at the outset of the jet age set 500 feet above ground level as the extent of private property ownership (at least in urban areas). 135 But, now, innovations in unmanned aviation and the nearly ubiquitous opportunity to fly at low altitudes are impacting common law conceptions of property and tort law as the federal government has begun to assert authority over all airspace "above the grass." For startup commercial UAV firms, therefore, the practical question of who controls the sky may be as important and uncertain as the academic question that asks who owns the sky. This Part addresses these questions, first, by explaining the threshold legal principles or federalism and preemption involved in the regulation of drones, and, second, by overviewing common law matters impacting and impacted by the operation of civil and commercial UAVs.

\section{A. Federalism and Preemption}

The preemptive power of the federal government over state and local authorities - and to a lesser extent, state authorities over local officials-in matters involving the national airspace is a cornerstone of aviation law. 136 As a starting point, the

134 The Roman doctrine of cujus est solum ejus usque ad coelom- "for whoever owns the soil, it is theirs up to Heaven ..."--controlled air rights until the mid-1940s, when private property rights were cut down to "the immediate reaches above the land," a phrase never linked to any specific altitude. See Causby, 328 U.S. at 260-61, 266 (1946).

135 See Florida v. Riley, 488 U.S. 445, 451 (1989).

136 In aviation and non-aviation context, courts have recognized two types of preemption: express and implied. Express preemption exists when the language of a federal law communicates an explicit intent by Congress to preempt state law. Whether a federal law preempts a state law is a question of congressional intent. Thus, if Congress intends to govern an issue exclusively it need only say so, as it has done in various areas. Implied preemption consists of "conflict preemption" and "field preemption." The former is said to exist either when compliance with both the federal and state laws is a physical impossibility, or when the state law stands as an obstacle to the accomplishment and execution of the full purposes and objectives of Congress. The latter exists when a court determines that a federal regulatory scheme is so pervasive that Congress must have intended to leave no room for a state to supplement it. Courts generally understand field preemption to mean that federal law "thoroughly occupies" the 
federal government, through the FAA, has exclusive and sovereign jurisdiction over the NAS pursuant to the Supremacy Clause of the Constitution. Congress preempted state and territorial regulation in the area of aviation safety by enacting the Federal Aviation Act of 1958.137 A single, uniform system of regulation was thought to be vital to increasing air safety, as was centralizing in a single authority and administrator the power to frame rules for the safe and efficient use of the nation's airspace. The reasoning underlying this was plain:

[A]viation is unique among transportation industries in its relation to the federal government-it is the only one whose operations are conducted almost wholly within federal jurisdiction, and are subject to little or no regulation by States or local authorities. Thus, the federal government bears virtually complete responsibility for the promotion and supervision of this industry in the public interest. 138

Whether and how to extend this legal precedent to the operation of drones flying beneath the NAS is indefinite, however. 139

"legislative field" in question, e.g., the field of aviation safety. Field preemption analysis has come up frequently before courts, particularly in the arena of aviation safety. The Supreme Court has emphasized a presumption against preemption. See, e.g., Morales v. Trans World Airlines, Inc., 504 U.S. 374, 421 (1992) (Stevens, J., dissenting) ("[A]lthough I agree that the plain language of [the Airline Deregulation Act of 1978] pre-empts any state law that relates directly to rates, routes, or services, the presumption against pre-emption of traditional state regulation counsels that we not interpret [this law] to pre-empt every traditional state regulation that might have some indirect connection with, or relationship to, airline rates, routes or services unless there is some indication that Congress intended that result.").

137 Federal Aviation Act of 1958, Pub. L. No. 85-726, 72 Stat. 731 (1958) (codified as amended at 49 U.S.C. $§ \S 40101-49105)$. See also Abdullah v. Am. Airlines, Inc., 181 F.3d 363 (3d Cir. 1999).

138 Abdullah, 181 F.3d at 368 (citing S. REP. No. 85-1811, at 5 (1958)).

139 See generally Operation and Certification of Small Unmanned Aircraft Systems, 81 Fed. Reg. 42064, 42182 (June 28, 2016) (to be codified at 14 C.F.R. pts. 21, 43, 61, 91, 101, 107, 119, 133, 183) (citing Minimum Safe Altitudes: General, 14 C.F.R. $§ 91.119$ (2018)) ("[W]ith limited 
Adding doubt to this state of affairs is the FAA's statement that, with respect to drones, it would, "address preemption issues on a case-by-case basis rather than doing so in a rule of general applicability." 140 As to the regulation of "flight altitude, flight paths; operational bans; or any regulation of the navigable airspace," the FAA has declined to say whether local law is prohibited, stating instead that "consultation with the FAA is recommended." 141 Consequently, a patchwork of drone-centered statutes and ordinances has filled a regulatory vacuum and pitted federal and state laws against each other. 142

Indeed, UAV laws are not centralized like those that have defined the relationship between the federal government and state governments for manned aviation over the last half century. Several states have enacted drone specific laws in the absence of-or sometimes concurrently with-federal law. ${ }^{143}$ Not every state has enacted UAV related legislation, but as of 2018, every state had at least considered UAV legislation. 144 In the 2017 legislative session, for example, at least thirtyeight states considered UAV-related legislation. 145

exception, the small unmanned aircraft may not fly higher than 400 feet AGL, which further separates that aircraft operation from most mannedaircraft operations in the NAS.”).

140 Id. at 42119.

141 Id. at 42194.

142 See, e.g., Margot E. Kaminski, Drone Federalism: Civilian Drones and the Things They Carry, 4 CAL. L. REv. CIR. 57, 59 (2013) (arguing that the "complex space of privacy regulation is best left to the states").

143 Timothy M. Ravich, Commercial Drone Law: Digest of U.S. and Global UAS Rules, Policies, AND Practices 259-333 (2017).

144 Amanda Essex, Taking OfF: State Unmanned Aircraft Systems Policies 5 (2016), http://www.ncsl.org/Portals/1/Documents/ transportation/TAKING_OFF-STATE_\%20UNMANNED_\%20AIRCRAFT _SYSTEMS_\%20POLICIES_\%20\%28004\%29.pdf [perma.cc/J8KD-4T6B].

145 Current Unmanned Aircraft State Law Landscape, NAT'L ConF. ST. LEGISLATURES (Feb. 1, 2018), http://www.ncsl.org/research/transportation/ current-unmanned-aircraft-state-law-landscape.aspx [perma.cc/N8R94NY2]. Eighteen states, including Colorado, Connecticut, Florida, Georgia, Indiana, Kentucky, Louisiana, Minnesota, Montana, Nevada, New Jersey, North Carolina, Oregon, South Dakota, Texas, Utah, Virginia and Wyoming, passed twenty-four pieces of legislation during that time. Id. 
Undoubtedly, the validity of some of these laws will not be known for certain until, or unless, tested in federal courts.

\section{FiguRE 2. STATE UAS RULES \& LEGISLATION (2017)146}

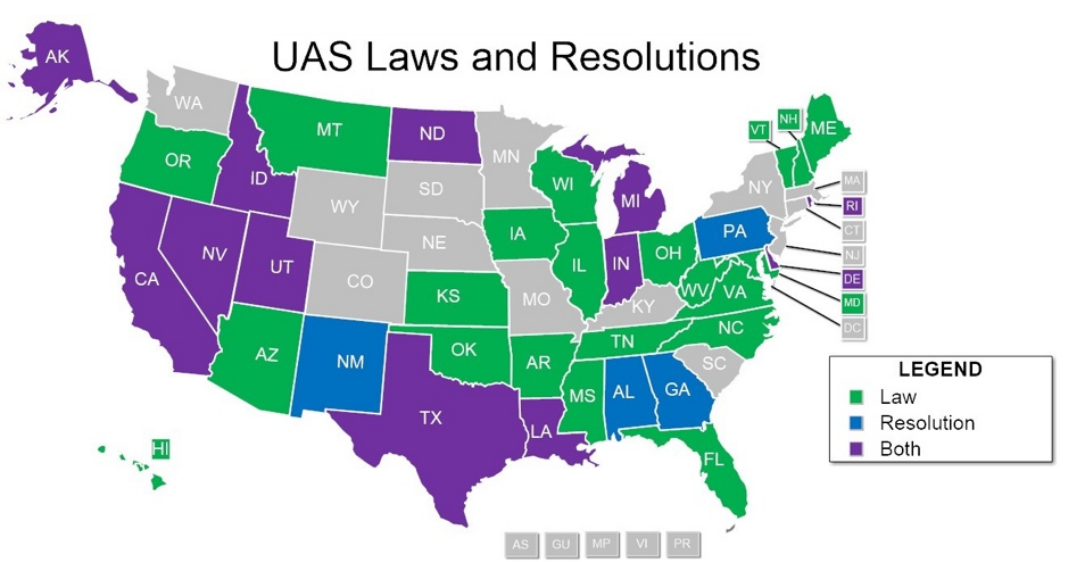

Interestingly, the force and effect that these laws might have is indefinite as several state legislatures have diluted their own laws by explicitly subordinating them to federal authority. Specifically, several states that have enacted UAV laws have expressed an intention not to interfere with federal law. 147 For example, Alaska's drone laws provide a stand-

146 EsseX, supra note 144, at 13.

147 For example, Arizona state law provides that "[e]xcept as authorized by law, a city, town or county may not enact or adopt any ordinance, policy or rule that relates to the ownership or operation of an unmanned aircraft system or otherwise engage in the regulation of the ownership or operation of an unmanned aircraft or unmanned aircraft system." Unlawful Operation of Model or Unmanned Aircraft; State Preemption; Classification; Definitions, ARIz. Rev. Stat. Ann. § 13-3729 (2016). Maryland codified a law that vests the state government with exclusive authority to regulate the testing or operation of unmanned aircraft systems, preempting the authority of counties and municipalities. Laws Governing the Testing and Operation of Unmanned Aircraft Systems, Md. Code Ann., Econ. Dev. § 14-301 (West 2017). In contrast to these jurisdictions, in North Carolina a unit of local government has explicit authority to adopt an ordinance to regulate the use of the local government's 
alone section entitled "Conformity to Federal Law," noting that state aviation authorities "may not adopt a regulation, order, or standard that is inconsistent or contrary to any act of the Congress of the United States or regulations promulgated or standards established."148 The law additionally provides that, "[a] regulation, order, or standard may not be adopted that duplicates any current rules or regulations issued by a federal agency, or that applies to aircraft, airports, or air navigation facilities owned or operated by the federal government." 149 No court has yet decided if this sort of language is consistent with existing federal law or whether existing federal aviation law would have priority over state laws respecting drones. 150

As federal and state UAV authorities jockey for position, 151 local authorities are beginning to regulate the operation of

property for the launch and recovery of UAS. Regulation of Launch and Recovery Sites, N.C. Gen. STAT. ANN. § 15A-300.2(b) (West 2014).

148 Conformity to Federal Law, AlaskA Stat. $§ 02.15 .030$ (West 1949).

149 Id.

150 The preemption contest between federal and state regulators also plays out between federal authorities and local lawmakers. For example, as previously discussed, the FAA contends that a city ordinance that bans anyone from operating UAV within the city limits, within the airspace of the city, or within certain distances of landmarks should be coordinated with the FAA as should operational UAS restrictions on flight altitude, flight path, operational bans, or any regulation of the navigable airspace. Operation and Certification of Small Unmanned Aircraft Systems, 81 Fed. Reg. 42064, 42194 (June 28, 2016) (to be codified at 14 C.F.R. pts. 21, 43, $61,91,101,107,119,133,183)$. According to a New York Times report, a Miami-Dade County's Ordinance that did just that ran afoul of this regulatory position. See MiAmi, Fla., ORDINANCES no. 13581, § 37-12 (2015). Lawyers from the FAA reportedly called the city council to make clear that the federal agency had ultimate control over airspace. See Cecilia Kang, F.A.A. Drone Laws Start to Clash with Stricter Local Rules, N.Y. Times (Dec. 27, 2015), https://www.nytimes.com/2015/12/28/technology/faa-drone-lawsstart-to-clash-with-stricter-local-rules.html.

151 In 2016, section 2142 of the Senate's proposed Federal Aviation Administration Reauthorization Act set out to broadly preempt both states and cities from enacting laws related to the design, manufacture, testing, licensing, registration, certification, operation, or maintenance of UAS, including airspace, altitude, flight paths, equipment or technology requirements, purpose of operations, and pilot, operator, and observer 
drones to the displeasure of state lawmakers. 152 For example, in 2014, the town of Deer Trail, Colorado, unsuccessfully attempted to authorize the issuance of licenses to allow residents to hunt and shoot down drones. 153 In November 2015, Chicago became the first major American city to pass a drone ordinance, reasoning that, "[n]ot withstanding [sic] those proposals being discussed in Washington, Chicago simply needs local laws in place to authorize the city to take action against those who operate drones recklessly and threaten public safety."154 Alongside these initiatives, North Carolina gave units of local government explicit authority to adopt ordinances to regulate the use of the local government's property for the launch and recovery of UAS. 155

qualifications, training, and certification. Federal Aviation Administration Reauthorization Act of 2016, S.2658, 114th Cong. (2016). See also NAT'L League Cities, Cities and Drones: What Cities Need to Know About Unmanned AERIAL Vehicles (UAVs) 17 (2016). The proposed law also sought to prohibit states and cities from including drones in laws related to nuisance, voyeurism, privacy, data security, harassment, reckless endangerment, wrongful death, personal injury, or property damage. Id. Although this preemption language was not included in the final reauthorization act approved by Congress, Congress may revisit the issue in the future. Id.

152 To access a broad listing of county and municipal UAS legislative proposals see SYRACUSE UNIV. INST. FOR NAT'L SECURITY \& Counterterrorism, Domesticating the Drone: Evaluating Privacy Policy In the Use of UnManNed AERIAL Vehicles Within the US, http://uavs.insct.org/local-regulation/ [perma.cc/FET4-P2PL].

153 See Katy Steinmetz, Colorado Town Won't Issue Drone-Hunting Licenses, TIME (Apr. 2, 2014), http://time.com/46327/drone-hunting-deertrail/ [perma.cc/LHA8-5SBC]; see also A. Michael Froomkin \& P. Zak Colangelo, Self-Defense Against Robots and Drones, 48 ConN. L. REv. 1 (2015); Cyrus Farivar, Man Shoots Down Neighbor's Hexacopter in Rural Drone Shotgun Battle, ARS TECHNIA (June 27, 2015, 1:05 PM), https://arstechnica.com/tech-policy/2015/06/man-shoots-downs-neighborshexacopter-in-rural-drone-shotgun-battle/ [perma.cc/XY2T-BAPZ].

154 Fran Spielman, Drone Regulations Fly with City Council, CHI. Sun Times (Nov. 18, 2015, 12:21 PM), http://chicago.suntimes.com/politics /drone-regulations-fly-with-city-council/ [perma.cc/E8MF-ALGX].

155 Regulation of Launch and Recovery Sites, N.C. Gen. Stat. AnN. $§$ 15A-300.2(b) (West 2014). 
Some states have cut off the ability of cities, municipalities, and local governments to regulate UAVs altogether. They have done so by enacting state statutes with preemptive effect over local UAV rules. Broadly, the power of a state to preempt and subordinate local law-referred to as Dillon's Rulederives from a narrow interpretation of a local government's authority, in which a local or municipal government (i.e., a "substate") may engage in an activity only if it is specifically sanctioned by the state government.156 For example, in December 2017, New Jersey lawmakers, in an effort to preempt local ordinances that may vary, advanced laws criminalizing the operation of a drone while drunk. 157

A number of other states have exerted their authority over local UAV proposals and rules:

- Alaska state law preempts local law with respect to images captured by drone, stating, "[a] municipality may not adopt an ordinance that permits the release of images captured by an

156 Nat'l League of Cities, City Rights in an Era of Preemption: A StATE-BY-STATE ANALYSIS: 2018 UPDATE, https://www.nlc.org/sites/default /files/2017-03/NLC-SML\%20Preemption\%20Report\%202017-pages.pdf [perma.cc/9K92-6KT2]. See also John F. Dillon, Commentaries on the LAW OF MUNICIPAL CORPORATIONS $§ 237$ (5th ed. 1911). The following thirtynine states employ Dillon's Rule to all municipalities: Arizona, Arkansas, Connecticut, Delaware, Georgia, Hawaii, Idaho, Kentucky, Maine, Maryland, Michigan, Minnesota, Mississippi, Missouri, Nebraska, Nevada, New Hampshire, New York, North Carolina, North Dakota, Oklahoma, Pennsylvania, Rhode Island, South Dakota, Texas, Vermont, Virginia, West Virginia, Washington, Wisconsin and Wyoming. Eight states employ the rule for only certain municipalities: Alabama, California, Colorado, Illinois, Indiana, Louisiana and Tennessee. The only exception to the exclusive selection of home rule or Dillon's Rule is Florida, which employs home rule but reserves taxing authority for the state. See Jesse J. Richardson, Jr. et al., Is Home Rule the Answer? Clarifying the Influence of Dillon's Rule on Growth Management 1 (Brookings Inst. Ctr. on Urban and Metro. Pol'y, Discussion Paper, 2003), https://www.brookings.edu/research/is-home-rulethe-answer-clarifying-the-influence-of-dillons-rule-on-growthmanagement/ [perma.cc/MS5X-BA2J].

157 Michael Catalini, Don't Drink and Drone: New Jersey Considering New Law, SeAtTle Times, https://www.seattletimes.com/nation-world/newjersey-considers-barring-operating-a-drone-while-drunk/ (last modified Dec. 5, 2017, 1:22 PM). 
unmanned aircraft system in a manner inconsistent with Alaska Stat. 18.65.903," which governs the retention of images. 158

- Arizona state law provides that "[e]xcept as authorized by law, a city, town or county may not enact or adopt any ordinance, policy, or rule that relates to the ownership or operation of an unmanned aircraft system or otherwise engage in the regulation of the ownership or operation of an unmanned aircraft or unmanned aircraft system. Any ordinance, policy or rule that violates this subsection, whether enacted or adopted by the city, town or county before or after [the effective dates of this section], is void." 159

- Maryland codified a law that vests the state government with exclusive authority to regulate the testing or operation of unmanned aircraft systems, preempting the authority of counties and municipalities: "Only the State may enact a law or take any other action to prohibit, restrict, or regulate the testing or operation of unmanned aircraft systems in the State."160 As such, the law "(1) preempts the authority of a county or municipality to prohibit, restrict, or regulate the testing or operation of unmanned aircraft systems; and (2) supersedes any existing law or ordinance of a county or municipality that prohibits, restricts, or regulates the testing or operation of unmanned aircraft systems."161

- In 2016, Rhode Island enacted its first drone law, giving the state and the Rhode Island Airport Cooperation exclusive authority to regulate "any object capable of flying that is remotely controlled and flies autonomously through software controlled flight plans embedded in the object's system by a global-position system, commonly

158 Regulation of Unmanned Aircraft Systems, ALASKA STAT. $\S 29.35 .146$ (West 2014).

159 ArIZ. Rev. Stat. ANN. § 13-3729 (2016).

160 Md. Code AnN., Econ. Dev. § 14-301 (West 2015).

161 Id. 
known as unpiloted aerial vehicles, remotely piloted aircraft, drones, or unmanned aircraft systems." But all of this may be for naught as the law concludes by stating that "[i]f federal law preempts any provision of this chapter, that provision shall not apply." 162

- No locality in Virginia is permitted to regulate the use of a privately owned, unmanned aircraft system within its boundaries. 163

In respect of the foregoing, the FAA issued a fact sheet titled "State and Local Regulation of Unmanned Aircraft Systems (UAS)" in December 2015.164 The fact sheet provides that "[s]tate and local restrictions affecting UAS operations should be consistent with the extensive federal statutory and regulatory framework pertaining to control of the airspace, flight management and efficiency, air traffic control, aviation

162 An Act Relating to Aeronautics-Unpiloted Aerial Vehicle Regulation, 2016 R.I. Pub. Laws Ch. 16-256; An Act Relating to Aeronautics-Unpiloted Aerial Vehicle Regulation, 2016 R.I. Pub. Laws Ch. 16-261.

163 Local Regulation of Certain Aircraft, VA. CodE ANN. § 15.2-926.3 (2016). See also Letter from Mark R. Herring, Attorney General, Commonwealth of Virginia, to Scott A. Surovell, Member, House of Delegates (July 13, 2015) ("[I]t is my opinion that the federal Deregulation Act expressly preempts state or local regulation of the routes, rates, and services of commercial drones used to transport property across state lines. Furthermore, the Aviation Act and FMRA preempt state and local regulation of drone safety, operational standards, and airspace designations, including particular issues relating to drone certification, training, and licensure. There are certain exceptions to federal preemption ... States remain free to enact laws relating to drones if the laws fall outside the scope of the Aviation Act and FMRA and do not conflict with other federal laws or regulations. In particular, states may regulate small drones that are exempted from federal regulation under the FMRA, and they may also enact laws for drones that address issues of privacy and property and also criminal offenses, so long as the laws do not conflict with the language or purpose of any existing federal aviation law.").

164 Office of the Chief Counsel, Fed. Aviation Admin., State and Local Regulation of Unmanned Aircraft Systems (UAS) Fact Sheet (2015), https://www.faa.gov/uas/resources/uas_regulations_policy/media/ uas_fact_sheet_final.pdf [perma.cc/LQV6-V6CA] [hereinafter FACT SHEET]. 
safety, navigational facilities, and the regulation of aircraft noise at its source."165 In its fact sheet, the FAA noted:

Substantial air safety issues are raised when state or local governments attempt to regulate the operation or flight of aircraft. If one or two municipalities enacted ordinances regulating UAS in the navigable airspace and a significant number of municipalities followed suit, fractionalized control of the navigable airspace could result. In turn, this "patchwork quilt" of differing restrictions could severely limit the flexibility of FAA in controlling the airspace and flight patterns, and ensuring safety and an efficient air traffic flow. A navigable airspace free from inconsistent state and local restrictions is essential to the maintenance of a safe and sound air transportation system. 166

165 Id. at 1. See Troy A. Rule, Airspace in an Age of Drones, 95 B.U. L. REv. 155 (2015); Troy A. Rule, Take Cover Against This Drone Attack, WaLL ST. J. (Mar. 29, 2016, 6:37 PM), https://www.wsj.com/articles/take-coveragainst-this-drone-attack-1459291069 (opposing a proposed law that would have made the FAA "the nation's sole drone regulator" because "[i]f the provision [were] signed into law, drone operators with FAA authorizations [would] be free to ignore state and local drone-use restrictions" and "[l] andowners and local governments [would] have a difficult time keeping unwelcome drones out of backyards and neighborhoods"). What role states might play in regulating drones is unclear. The FAA's historic territoriality and ongoing practice of overriding and preempting state and local laws in the UAV space renders dubious proposals calling for a more flexible approach in federal-state dealings with respecting to emerging technologies. Compare supra notes 150 and 151 and accompanying text, with Sara E. Light, Advisory Nonpreemption, 95 WASH. U. L. REV. 325, 344 (2017) (positing the concept of "advisory nonpreemption" whereby an agency issues a "public statement in policy guidance in response to a federalism disruption-before it initiates any notice-and-comment rulemaking-about how it interprets its delegated authority from Congress, and whether its interpretation gives it the power to regulate the innovation").

166 FACT SHEeT, supra note 164, at 2 (citing Montalvo v. Spirit Airlines, 508 F.3d 464 (9th Cir. 2007), French v. Pan Am Express, Inc., 869 F.2d 1 (1st Cir. 1989), Arizona v. United States, 567 U.S. 387, 401 (2012) ("Where Congress occupies an entire field . . . even complimentary state regulation is impermissible. Field preemption reflects a congressional decision to foreclose any state regulation in the area, even if it is parallel to federal 
Although the FAA's fact sheet is not a formal rule, courts have deferred to it as the FAA's interpretation of its own rule.

In Singer v. City of Newton, for example, a federal judge relying on the FAA's fact sheet struck down an ordinance passed by the City of Newton, Massachusetts that required drone owners to register their devices and prohibited them from flying out of the operator's line of sight or in certain areas without permit or express permission. 167 The ordinance, designed to protect the privacy interests of Newton residents, was "intended to be read and interpreted in harmony with all relevant rules and regulations of the Federal Aviation Administration, and any other federal, state and local laws and regulations." 168 The ordinance specifically: (1) required the registration of all drones (i.e., model and commercial); (2) prohibited pilotless aircraft flight below 400 feet over any private property without the express written permission of the property owner; (3) prohibited pilotless aircraft flight over public property without prior permission from the city; and (4) banned the flight of pilotless aircraft "at a distance beyond the visual line of sight of the Operator." 169 Under the doctrine of conflict preemption, the court found that federal law preempted the Newton ordinance. 170

As the Singer court reasoned, the FAA has exclusive jurisdiction over UAV operations in the NAS because Congress vested it with authority to regulate the areas of airspace use, management and efficiency, air traffic control, safety, navigational facilities, and aircraft noise at its source. 171 Indeed, Congress directed the FAA to "develop

standards.”), and Morales v. Trans World Airlines, Inc., 504 U.S. 374, 38687 (1992)).

167 Singer v. City of Newton, No. 17-10071-WGY, 2017 WL 4176477 (D. Mass. Sept. 21, 2017).

$168 \mathrm{Id}$. at *2.

169 Id.

170 Id. at *6-8. See also John Goglia, What's the Status of Local Drone Ordinances after the Singer Decision?, ForBEs (Sept. 25, 2017, 11:10 AM), https://www.forbes.com/sites/johngoglia/2017/09/25/whats-the-status-oflocal-drone-ordinances-post-singer-decision/ [perma.cc/7FJQ-3G6J].

171 FACT SHEET, supra note 164, at 1 ("Why the Federal Framework") (citing 49 U.S.C. $\S \S 40103$, 44502, and 44701-35). 
plans and policy for the use of the navigable airspace and assign by regulation or order the use of the airspace necessary to ensure the safety of aircraft and the efficient use of airspace."172 Congress also directed the FAA to "prescribe air traffic regulations on the flight of aircraft (including regulations on safe altitudes)' for navigating, protecting, and identifying aircraft; protecting individuals and property on the ground; using the navigable airspace efficiently; and preventing collision between aircraft, between aircraft and land or water vehicles, and between aircraft and airborne objects."173 The FAA's position-that its regulatory authority over matters pertaining to aviation safety ensures the maintenance of a safe and sound air transportation system and of navigable airspace free from inconsistent restrictionis well supported in the law. 174 Naturally, then, the FAA's final operational rule for routine commercial use of small unmanned aircraft_codified at Part 107-is predicated upon these broad regulatory powers respecting aviation safety.

Yet, notwithstanding its expansive and exclusive authority over the NAS, the FAA has specifically declined to address whether its authority with respect to drones preempts state and local UAV laws and ordinances. Instead, the preemptive effect of Part 107 depends upon the purpose and terms of the state law and its relationship to any applicable federal law. The Preamble to Part 107, in fact, identifies several matters over which local regulation could be appropriate:

- This rule [Part 107] does not address preemption issues because those issues necessitate a case specific analysis that is not appropriate in a rule of general applicability. The FAA notes, however, that state governments have historically been able

172 Id. (citing 49 U.S.C. $§ 40103(\mathrm{~b})(1))$.

173 Id. at 1-2 (citing 49 U.S.C. $\S 40103(b)(2)$ ).

174 Id. at 2 ("A consistent regulatory system for aircraft and use of airspace has the broader effect of ensuring the highest level of safety for all aviation operations."). 
to regulate the takeoffs and landings of aircraft within their state boundaries. 175

- The FAA is not persuaded that including a preemption provision in the final rule is warranted at this time. Preemption issues involving small UAS necessitate a case-specific analysis that is not appropriate in a rule of general applicability. Additionally, certain legal aspects concerning small UAS use may be best addressed at the state or local level. For example, state law and other legal protections for individual privacy may provide recourse for a person whose privacy may be affected through another person's use of a UAS. 176

- Adjudicating private property rights are beyond the scope of this rule. However, the provisions of this rule are not the only set of laws that may apply to the operation of a small UAS. With regard to property rights, trespassing . . . may be addressed by State and local trespassing laws. 177

- [UAS operators] who do not have the facility owner's permission to operate a UAS near or over the perimeter or interior of amusement parks and attractions may be violating state or local trespassing laws. 178

- State law and other legal protections may already provide recourse for a person whose individual privacy, data privacy, private property rights, or intellectual property rights may be implicated by a remote pilot's civil or public use of a UAS. 179

- State law and other legal protections for individual privacy may provide recourse for a person whose privacy may be affected through another person's use of a UAS. 180

175 Operation and Certification of Small Unmanned Aircraft Systems, 81 Fed. Reg. 42064, 42189 (June 28, 2016) (to be codified at 14 C.F.R. pts. 21, 43, 61, 91, 101, 107, 119, 133, 183).

176 Id. at 42194.

177 Id. at 42119.

178 Id. at 42132 .

179 Id. at 42192.

180 Id. at 42194. 
- Substantial air safety issues are implicated when state or local governments attempt to regulate the operation of aircraft in the national airspace. The Fact Sheet provides examples of State and local laws affecting UAS for which consultation with the FAA is recommended and those that are likely to fall within State and local government authority. For example, consultation with FAA is recommended when state or local governments enact operational UAS restrictions on flight altitude, flight paths; operational bans; or any regulation of the navigable airspace. 181

Ultimately, commercial UAS firms, together with their investors and clients, currently operate in an evolving legal environment in which there exist different and sometimes disharmonious rules at the national, state, and local levels. 182

\section{B. New Drone Business Issues and Common Law Resilience}

While the national government frequently prevails on questions of federalism and preemption discussed in Section III.A, supra, the FAA has stipulated that state and local authorities have "police powers" in five areas that are generally not subject to federal regulation: land use, zoning, privacy, trespass, and law enforcement.183 In this context,

181 Id.

182 President Donald Trump issued an executive order in late 2017 that created a UAS Integration Pilot Program designed for state, local, and tribal governments to accelerate the safe integration of UAS operations and allowance of more advanced UAS operations, such as beyond visual line-ofsight or over people. See, e.g., Jonathan Vanian, Everything to Know about President Donald Trump's New Drone Program, ForTune (Oct. 25, 2017), http://fortune.com/2017/10/25/donald-trump-drone-program/ [perma.cc/C9NW-ATC9].

183 Operation and Certification of Small Unmanned Aircraft Systems, 81 Fed. Reg. at 42194. The federal government's exclusive sovereignty of the national airspace does not preclude states or municipalities from passing any valid aviation regulations. See Singer v. City of Newton, No. 17 10071-WGY, 2017 WL 4176477, at *3 (D. Mass. Sept. 21, 2017) (citing 
many state and local governments have their own sets of UAV laws, including reckless endangerment laws, a requirement for law enforcement to obtain a warrant prior to using a UAV for surveillance, a prohibition on the use of UAVs for voyeuristic purposes, a ban on the deployment of UAVs for hunting or fishing, and a bar on the weaponization of UAVs. 184 Meanwhile, the ways in which drones infringe on traditional property and privacy rights occupies scholarly and policy-based discussions about drones. 185 But, the key civil aspects of the common law that give insight into the emerging business law dimension of civil drones are underdiscussed.

Drone owners, operators, manufacturers, and even regulators themselves are prone to the usual variety of consumer protection, class action, and breach of contract disputes in which traditional, non-IoT products are at issue. Some of the most interesting examples include:

- Deceptive business practices. In 2015, startup Lily Robotics gained the attention of millions of viewers-and $\$ 15$ million in investment and $\$ 34$ million in preorders-after posting a gripping video showing a camera drone that, among other things, automatically followed its operator. But, in 2017, the company shut down before shipping any of its $\$ 499$ devices. The San Francisco District Attorney filed a civil consumer protection suit

Braniff Airways v. Nebraska State Bd. of Equalization \& Assessment, 347 U.S. 590, 595 (1954)).

184 See Timothy M. Ravich, Commercial Drone Law: Digest of U.S. and Global UAS Rules, Policies, and Practices ch. 10 (2017); see also FED. Aviation Admin., U.S. DeP'T OF TransP., LaW EnForcement Guidance FOR SUSPECTED UNAUTHORIZED UAS OPERATIONS (2017), https://www.faa.gov/uas/resources/law_enforcement/media/FAA_UASPO_LEA_Guidance.pdf [perma.cc/4PQX-7H68].

185 See, e.g., Jeramie D. Scott, Drone Surveillance: The FAA's Obligation to Respond to the Privacy Risks, 44 ForDHAM URB. L.J. 767 (2017); Hillary B. Farber, Keep Out! The Efficacy of Trespass, Nuisance and Privacy Torts as Applied to Drones, 33 GA. ST. U. L. REV. 359 (2017); Jake Laperruque, Preventing An Air Panopticon: A Proposal for Reasonable Legal Restrictions on Aerial Surveillance, 51 U. RICH. L. REV. 705 (2017); Timothy T. Takahashi, Drones and Privacy, 14 Colum. SCI. \& TECH. L. REV. 72 (2012). 
alleging the company had published a false and misleading video showing potential customers a device created almost entirely with technology from its rivals. 186 Similarly, in 2017, a Brooklyn federal court ordered a man to spend five years in prison and to pay almost $\$ 1.5$ million in restitution for sending out phony public releases about a drone company that existed only on paper. 187

- Class actions. In February 2017, commercial UAV operators sued DJI Technology, Inc. for allegedly harmful firmware updates. 188 Meanwhile, the FAA is itself a defendant in a class action lawsuit pending in federal district court in Arkansas that seeks refunds from the agency of monies UAV owners paid to register their drones - a regulatory requirement struck down by a federal court as violating the express terms of the FMRA. 189

186 Ryan Mac, How an Allegedly Fake Video Killed a Much-Hyped Drone Startup, ForBes (Jan. 13, 2017, 8:30 PM), https://www.forbes.com/sites/aarontilley/2017/01/13/lawsuit-killed-lilyrobotics-drones/ [perma.cc/CTA2-TF49]. See also Ryan Mac \& Aaron Tilley, Failed Drone Startup Lily Robotics Raided for Possible Criminal Investigation, Sources Say, ForBEs (Jan. 31, 2017, 3:39 PM), [perma.cc/2XE3-N4HX].

187 Kathleen Culliton, Sham Drone Company Head Fined $\$ 1.5 M$ in Brooklyn Court: Feds, PATCH (Dec. 6, 2017, 3:36 PM), https://patch.com/newyork/heights-dumbo/sham-drone-company-head-fined-1-5m-brooklyncourt-feds [perma.cc/BK7D-RXCZ].

188 Kathryn Rattigan, DJI Drone Manufacturer Hit with Class Action Lawsuit over Firmware Update, DATA PRIVACY + SECURITY INSIDER (Feb. 23, 2017), https://www.dataprivacyandsecurityinsider.com/2017/02/dji-dronemanufacturer-hit-with-class-action-lawsuit-over-firmware-update/ [perma.cc/L7S2-FJ5B].

189 See, e.g., Lance Ulanoff, It's Been 3 Months and the FAA Still Hasn't Refunded My \$5 Drone Registration Fee, MASHABLE (Oct. 10, 2017), http://mashable.com/2017/10/10/faa-drone-registration-refund/ [perma.cc/4TNW-VRFC]; Class Action Lawsuit Filed Against the FAA over Drone Registry, AERo-News NeTworK (Oct. 18, 2017), http://www.aeronews.net/Subscribe.cfm?do=main.textpost\&id=9621c552-d8ce-493a-88d825aa57e6015f [perma.cc/4D4B-5TD3]; see also infra Section IV.D. 
- Business dealings. Drone racing is rapidly gaining popularity. ESPN and Sky Sport broadcast events of the Drone Racing League, which has raised millions in investment seed money. In 2017, however, two Southern California tech enthusiasts sued the Drone Racing League, Inc. for breach of contract, fraud, and breach of fiduciary duty, claiming that they were promised, but never received, a one-third ownership interest in exchange for providing ideas for the league. 190

- Negligence. A woman sued a University of Southern California Pi Kappa Phi fraternity chapter when a drone photographing attendees at a party fell and allegedly inflicted severe head injuries. 191 Several months later, in Massachusetts, wedding guests sued the groom after a drone he brought to the reception flew and crashed into them, allegedly causing permanent physical and emotional injury. 192

- Contracts. Some user agreements provided by drone manufacturers allow access not only to the owner and operator's tablet or computer used to operate a drone, but also to the entire system that tablet or computer is connected to, effectively

190 Scott Graham, Drone Racing League Was Our Idea, Tech Enthusiasts Say, LAW.COM (Oct. 4, 2017, 10:37 AM), https://www.law.com/sites/almstaff/2017/10/04/drone-racing-league-wasour-idea-tech-enthusiasts-say/?slreturn=20171110090122 [perma.cc/ W4RW-KECS]. See also Complaint, Laub v. Horbaczewski et al., No. 2:17cv-06210-JAK-KS (Cal. Super. Aug. 22, 2017), https://www.cozen.com/Templates/media/files/publications/alerts/Laub\%20 v_\%20Horbaczewski\%2017-06210\%20Complaint.pdf [perma.cc/DD3WDXVS].

191 See Sama Shah, Party Guest Sues Fraternity over Falling Drone, DAILY TROJAN (Sept. 28, 2016), http://dailytrojan.com/2016/09/28/partyguest-sues-fraternity-falling-drone/ [perma.cc/TG4V-8932].

192 Kiera Blessing, Wedding Drone Crash Leads to Guests' Lawsuit, EAGLE-TRIB. (Dec. 16, 2016), http://www.eagletribune.com/news/weddingdrone-crash-leads-to-guests-lawsuit/article_9bdf14d4-c3bd-11e6-87dc0752f3c938b6.html. 
giving the drone manufacturer access to highly proprietary and private imagery and videos. 193

- Product liability. In 2016, Bradley Telling, the owner of a DJI Phantom 3 drone, filed a putative class action lawsuit against DJI Technology, Inc. in Los Angeles Superior Court alleging violations of California's Unfair Competition Law and Consumer Legal Remedies Act.194 The company refused to give him a refund after his drone went out of control and was lost despite DJI's promotion of the device's "return home" feature. 195

Beyond traditional contract and tort claims, intellectual property issues connected to drones are likely to give rise to extensive litigation.196 For now, the patent system is managing an ever-increasing number of exceptional ideas. For example, IBM obtained a patent for technology that makes it possible for one drone to hand off packages to another drone. 197 In 2014, Disney filed several patent applications, including one for drones that could carry marionette-version characters, "flixels," that could replace fireworks with lit-up substitutes, and drones that could carry around large aerial projection screens.198 Relatedly, the halftime show of Super

193 See e.g., Dyan Gibbens, Grounded: How to Integrate Ethics into Your Drone Strategy, HARV. Bus. REV. (May 22, 2017), https://hbr.org/2017/05/grounded-how-to-integrate-ethics-into-your-dronestrategy [perma.cc/A56U-5UW3].

194 Rick Archer, Drone Didn't Come Home as Promised, Suit Claims, LAW360 (June 28, 2016, 6:18 PM), https://www.law360.com/articles/811782/drone-didn-t-come-home-aspromised-suit-claims. See Bradley Scott Telling v. DJI Tech. Inc., No. BC625051, 2016 WL 3647202 (Cal. Super. June 27, 2016).

195 See Bradley Scott Telling v. DJI Tech. Inc., 2016 WL 3647202.

196 See, e.g., SZ DJI Tech. Co., Ltd. v. Yuneec Int'l Co., Ltd., No. 516CV-595 BRO (KKx), 2016 WL 8931302 (C.D. Cal. Oct. 13 2016) (patent dispute regarding a system for controlling UAVs and tracking targets).

197 See e.g., Brett Williams, IBM Wants Future Delivery Drones to Pass Off Your Packages in Mid-air, MAshable (Apr. 26, 2017), http://mashable.com/2017/04/26/ibm-delivery-drone-patent/ [perma.cc/5N49-JDKD].

198 See e.g., Jordan Crook, Disney Files Patents to Use Drones in Park Shows, TECHCRUNCH (Aug. 27, 2014), 
Bowl LI in February 2017 featured a drone show-a synchronized swarm of three hundred of Intel's illuminated "Shooting Star" drones flying over and behind Lady Gaga in the formation of an American flag as she recited the Pledge of Allegiance from the roof of the stadium.199 Altogether, while the diversity of legal claims and theories connected to drones is and will be unprecedented, the common law appears well built to adapt to and resolve disputes in the information age.

\section{CRITIQUING THE UAV REGULATORY ENVIRONMENT}

On June 22, 2017, newly inaugurated President Donald J. Trump and Vice President Mike Pence welcomed the CEOs of several commercial drone companies to the East Room of the White House as part of the American Leadership in Emerging Technology event. Organized by the Office of Science and Technology Policy, the event brought together venture capitalists, wireless communication company executives, and White House staff to discuss ways in which the administration could promote the development and commercialization of emerging technologies. 200 There, addressing a president who

https://techcrunch.com/2014/08/27/disney-files-patents-to-use-drones-inpark-shows/ [perma.cc/L4Y4-YTV3].

199 See Ted Greenwald, Intel Basks in Afterglow of Super Bowl Light Show Launched by Its Drones, Wall. ST. J. (Feb. 6, 2017, 6:18 PM), https:/www.wsj.com/articles/intel-basks-in-afterglow-of-super-bowl-lightshow-launched-by-its-drones-1486423132 ("Many TV viewers thought they were watching a live light show, a perception Intel didn't go out of its way to dispel. 'Our drones have returned to the ground after an amazing \#PepsiHalftime show,' the company tweeted shortly afterward."); see also Henri Gendreau \& Alan Levin, Lady Gaga Halftime Drone Swarm Was Pretaped to Shield Crowd, BloomBerg: Pursuits (Feb. 7, 2017, 5:00 AM), https://www.bloomberg.com/news/articles/2017-02-07/lady-gaga-s-halftimedrone-swarm-was-pretaped-to-shield-crowd [perma.cc/U6NQ-BQT7] ("Intel ... produced a holiday show with Disney in Florida . . . with drones forming a green Christmas tree and a blue dove, among other effects.").

200 See, e.g., David Shepardson, Trump Meets Wireless, Drone Executives on New Technologies, REUTERs (June 22, 2017), https://www.reuters.com/article/us-usa-trump-tech/trump-meets-wirelessdrone-executives-on-new-technologies-idUSKBN19D2DA [perma.cc/6HBL$5 \mathrm{~S} 52]$. 
made deregulation a centerpiece of his candidacy and who just days after taking office signed an executive order requiring federal agencies to eliminate two regulations for every new one created,201 the CEO of a drone software and hardware company lobbied for something unexpected-more regulation.

"This is actually the one industry where we actually need a little bit more regulation," PrecisionHawk CEO Michael Chasen said, "because the default is actually limiting what drone technology can do." 202 He continued, "[w]e need the FAA and the other regulatory bodies to have a little bit more power to regulate opening up those opportunities so we can stay competitive with other countries. It's one of the few areas we'd like to see a little more regulation to actually open up opportunity." 203 An industry overview by Goldman Sachs similarly noted, "[t]he rapid growth of the drone industry has outpaced the development of rules and systems to govern their use. This uncertainty weighs on innovation and commercial adoption, but anticipated regulatory clarity should unlock demand."204

In fact, the FAA codified a national set of commercial drone regulations in mid-2016 in the form of Part 107.205 But, getting there was difficult-unnecessarily so, in several instances. For example, the FAA failed to act or was slow to act despite its authority and Congress's directive to do so. And where the FAA's authority to act was only arguable, the FAA acted definitively and in ways that apparently conflicted with

201 See e.g., Damian Paletta \& Michael C. Bender, Trump Signs Executive Order to Cut, Restrict Regulations, WALL ST. J. (Jan 30, 2017, 2:44 PM), https://www.wsj.com/articles/trump-signs-executive-order-to-cutrestrict-regulations-1485790245; see also Christopher DeMuth, Trump vs. the Deep Regulatory State, WALL ST. J. (Nov. 17, 2017, 6:10PM), https://www.wsj.com/articles/trump-vs-the-deep-regulatory-state1510952431.

202 PrecisionHawk (@PrecisionHawk), TwITTER (June 22, 2017, 12:12 PM), https://witter.com/i/web/status/877922181727928320 [perma.cc/P2C3-Y5WU]

203 Id.

204 Drones, GoLDMAN SACHS, http://www.goldmansachs.com/ourthinking/technology-driving-innovation/drones/ [perma.cc/WAQ9-VM4E]. 205 Small Unmanned Aircraft System, 14 C.F.R. § 107 (2018). 
its prior practices and policies. In yet other instances, the FAA acted on incomplete data. Finally, and perhaps most troublesome, the FAA acted where Congress explicitly deprived it of authority to act. This Section will explore each of these scenarios, primarily to illustrate both the corresponding regulatory burdens imposed on emerging UAV firms and to draw broader lessons about how precautionary principle-based law and policymaking can be flawed as applied to the IoT.206

\section{A. Regulatory Timing}

The FAA took years to arrive at a regulatory framework for drones-a reality that alone suppressed innovation. The title of a 2014 Fortune article captured the mood of the drone business community: "Is the FAA Limiting Drone Innovation?"207

Indeed, according to a lobbyist at the Washington, D.C.based drone-advocacy firm Association for Unmanned Vehicle Systems International ("AUVSI"), delay by the FAA in clearing commercial UAS operations would result in the loss of $\$ 27$ million per day. 208 In fact, the current drone economy began with investments and activities dating back to approximately 2006, but a legal regime dedicated to supporting the civil UAV space did not arise until almost six years later.

In 2012, Congress enacted the FMRA, a forward-looking law that required the FAA to create a regulatory framework to "safely accelerate the integration of civil unmanned aircraft systems into the national airspace system ... not later than"

206 As Professor Cass Sunstein has observed, precautionary principlebased policymaking presents a test that many of history's most significant innovations would have failed, including airplanes, air conditioning, antibiotics, automobiles, chlorine, the measles vaccine, open-heart surgery, radio, refrigeration, the smallpox vaccine, and X-rays. $C f$. DANIEL KAHneman, ThinkIng, FAST AND SlOW 350 (2011).

207 Mehboob Jeelani, Is the FAA Limiting Drone Innovation?, ForTunE (Aug. 28, 2014), http://fortune.com/2014/08/28/faa-limiting-droneinnovation/ [perma.cc/E4TR-7QAD].

208 See e.g., id. 
September 30, 2015.209 Congress also mandated that the FAA establish recommendations that define acceptable standards for the operation and certification of civil UAVs, ensure that any civil UAVs have sense and avoid capability, establish standards and requirements for the operator and pilot of a civil unmanned aircraft system, and project the best methods to enhance the technologies necessary to achieve the safe and routine operation of civil UAVs in the NAS.210 The FMRA permitted a "phased-in" approach for civil UAV integration, but it targeted August 2014 for publication of a final rule governing regularized UAV operations.211 The FAA did not meet this deadline.

Rather, in September 2013, various federal authorities released a jointly prepared comprehensive plan (the "Plan") that set out several strategic goals for the phased-in integration of UAVs into the NAS. 212 It was widely anticipated as the green light commercial UAVs had been waiting for years to issue. The Plan gave priority to "public" UAVs, but forestalled "civil" UAV integration. It speculated that civil UAVs would fly without special authorization by 2015, with "routine" UAV operations by 2020.213 The Plan also projected the release of a Notice of Proposed Rulemaking for UAVs in early 2014 and an Integration Roadmap laying

209 FAA Modernization \& Reform Act of 2012, Pub. L. 112-95, $\S \S$ 332(a)(1), (a)(3), 126 Stat. 11 (2012). Congress has considered amending the FMRA to address privacy-related concerns arising from drone operations. Drone Aircraft Privacy and Transparency Act of 2013, H.R. 1262, 113th Congress (2013).

210 FAA Modernization \& Reform Act of $2012 \S 332(\mathrm{a})(2)$.

$211 I d$. at $\S \S 332(\mathrm{a})(2)(\mathrm{C}),(\mathrm{a})(3)$.

212 See Joint Planning and Dev. Office, Unmanned Aircraft Systems (UAS) Comprehensive Plan 3 (2013) (the "Plan").

213 Id. at 9. The Plan anticipated that UAV within visual line-of-sight would operate in the NAS. In addition to the goals of studying acceptable levels of automation for UAS in the NAS and harmonizing UAS operations under international UAS protocols, the Plan also addressed important "nonsafety related issues" such as privacy and national security, including cyber and communications security. $I d$. at 7 . To that end, the Plan initiated a program for the establishment of UAS test ranges to "help inform future rulemaking activities and other policy decisions related to safety, privacy, and economic growth.” Id. at 15, § 2.4. 
out a rolling five-year plan for implementing UAV operations into the NAS. 214 No Notice of Proposed Rulemaking was issued until 2015, 215 though the FAA did release an "Integration of Civil Unmanned Aircraft Systems (UAS) in the National Airspace (NAS) Roadmap" (the "Roadmap") on November 7, 2013.216 Like policy documents before it, the Roadmap was disappointing for its largely aspirational nature, forecasting an evolutionary transition from "accommodating" UAVs to "integrating" the technology within the NAS without also providing a specific timetable for implementation of the rules the FMRA mandated. 217

The Roadmap contemplated commercial UAV applications, including in the media and entertainment sector, ${ }^{218}$ but it did not go so far as to authorize commercial UAV use generally. In fact, it did the opposite. No person was authorized to operate a commercial UAV in the NAS without first obtaining specific authority and permission from the FAA in several ways. 219 First, private commercial UAV operators needed to obtain a Certificate of Authorization or Waiver ("COA") from the FAA to operate a UAV as a public entity, e.g., agencies receiving funding from the federal government, including police, fire rescue services, and public universities. 220 In this

214 Id. at $4,17$.

215 Operation and Certification of Small Unmanned Aircraft Systems, 80 Fed. Reg. 9544 (proposed Feb. 23, 2015) (to be codified at 14 C.F.R. pts. 21, 43, 45, 47, 61, 91, 101, 107, 183). See also FAA Releases Notice of Proposed Rulemaking for Small Unmanned Aircraft Systems, JonEs DAY (Mar. 2015), http://www.jonesday.com/FAA-Releases-Notice-of-ProposedRulemaking-for-Small-Unmanned-Aircraft-Systems-03-04-2015.

216 Fed. Aviation Admin., U.S. DeP’t of Transp., Integration of Civil Unmanned Aircraft Systems (UAS) in the National Airspace (NAS) ROADMAP (2013), http://www.faa.gov/uas/media/uas_roadmap_2013.pdf [perma.cc/2XXZ-92M3].

217 See id. at 21.

218 Id. at 7.

219 See Fed. Aviation Admin., U.S. Dep't of Transp., Order No. 8130.34D, Airworthiness CERTification of Unmanned Aircraft Systems AND OPTIONALly PilOted Aircraft (2008), https://www.faa.gov/regulations_policies/orders_notices/index.cfm/go/docu ment.information/documentID/1031867 [perma.cc/MB7Q-X6WD].

220 Id. 
manner, a private operator could fly a drone only by partnering with a public entity, such as a state university. ${ }^{221}$

A COA, as the FAA explains, "is an authorization issued by the Air Traffic Organization to a public operator for a specific UA activity."222 Obtaining a COA involves the completion of an application process involving

a comprehensive operational and technical review. If necessary, provisions or limitations may be imposed as part of the approval to ensure the UA can operate safely with other airspace users. In most cases, FAA will provide a formal response within 60 days from the time a completed application is submitted.223

Once issued, the COA expires on the stated termination date (usually two years) unless surrendered sooner by the proponent or revoked by the issuing agency.224 Substantively, a COA authorizes an operator to use defined airspace and includes special provisions unique to the proposed operation, for example, flying only under Visual Flight Rules and/or only during daylight hours.225 In any case, the COA pathway is not an easy or inexpensive route for civil UAV operators. Only 423

221 Additionally, the COA process produced the unusual result that private and public entities flying the same type of drone for the same purpose stood on different regulatory footing. For example, a public university could itself operate a drone for civil purposes by obtaining a COA, but a private university could not fly a drone for civil, non-recreational purposes without finding a public sponsor with a COA or otherwise establish that somehow it was flying as a public operator.

222 Certificates of Waiver or Authorization (COA), FED. AviATION ADMIN.,

https://www.faa.gov/about/office_org/headquarters_offices/ato/service_unit s/systemops/aaim/organizations/uas/coa/ [perma.cc/E4GU-KYQE] (last modified Mar. 9, 2018, 1:38 PM).

223 Id.

224 Fed. Aviation Admin., U.S. Dep't of Transp., Notice No. JO 7210.889, Unmanned Aircraft Operations in the National Airspace (NAS) ๆ 11(d)(2) (2015), https://www.faa.gov/documentLibrary/media/ Notice/N_JO_7210.889_Unmanned_Aircraft_Operations_in_the_NAS.pdf [perma.cc/4PY8-P2GN].

225 Certificates of Waiver or Authorization (COA), supra note 222. 
COAs were issued in 2013,226 demonstrating how relatively rare (lawful and/or known) civil UAV operations were.

Instead of a COA, commercial UAV operators can obtain a Special Airworthiness Certificate-Experimental Category ("SAC-EC") under 14 C.F.R. § 21.191 for limited purposes, including research and development, market surveying, and crew training. 227 For all intents and purposes, obtaining a special airworthiness certificate is not an effective option for civil and commercial UAS operators and owners given associated operational limitations and the rarity with which the FAA issues such authorizations. Indeed, a SAC-EC (appropriately) exacts a high burden of proof on the operators of experimental aircraft, requiring them to demonstrate "that their unmanned aircraft system can operate safely within an assigned flight test area and cause no harm to the public." 228 Moreover, "[e]xperimental certificate regulations preclude carrying people or property for compensation or hire."229 And, applicants bear the substantial burden of describing how their system is designed, constructed and manufactured, including engineering processes, software development and control, configuration management, and quality assurance procedures used, along with how and where they intend to fly. 230 Accordingly, in years past, the best option for civil drone operators was somehow to be a public operator or otherwise qualify as a public operator (e.g., in partnership with a public university or state agency) to obtain a COA from the FAA.

Section 333 of the FMRA presented an important and much-needed intermediate position between the SAC-EC and COA process-albeit another route laden with red tape. Section 333 mandates that the FAA: (1) identify and

\footnotetext{
226 See Fact Sheet-Unmanned Aircraft Systems (UAS), FED. AviATION ADMIN. (Feb. 15, 2015), https://www.faa.gov/news/fact_sheets/news_story.cfm?newsId=18297 [perma.cc/4Z95-NVXD].

227 Id

228 Civil Operations (Non-Governmental), Fed. Aviation Admin., https://www.faa.gov/uas/civil_operations/.

229 Id.

$230 I d$.
} 
determine UAS operations [that] pose the least amount of public risk and no threat to national security and could safely be operated in the NAS; and based on that assessment, (2) establish requirements for the safe operation of the UAS into the NAS. Within this framework, the FAA granted thousands of "333 exemptions" on a case-by-case basis to qualifying civil drone operators. This process was tedious for the regulators and the regulated as it required the FAA to evaluate every UAS operation individually. As such, in 2015, the FAA granted automatic "Blanket COAs" to those exempted from Section 333, allowing small drones weighing less than fiftyfive pounds to operate during daytime, within visual flight rule conditions, at specific altitudes, and outside of certain distances from airports and heliports. The Blanket COA also permitted small UAV operators to fly five nautical miles away from an airport with an operating control tower, three nautical miles from an uncontrolled airport with an instrument approach procedure, two nautical miles from all other airports, heliports and seaports, and at or below 200 feet above ground level. 231

While functional, the COA and Blanket COA process presented a barrier to entry without any corresponding empirical benefit in terms of safety or commerce. In fact, the Blanket COA merely sanctioned already safety-conscious operators to proceed without also deterring or educating unscrupulous operators. The result was not only frustration in the private sector, but also a disapproving report by the U.S. Department of Transportation ("DOT") Inspector General who ridiculed the FAA as having "limited knowledge of where UAS actually operate and limited means to oversee those exempted operators." 232

231 See generally Unmanned Aircraft Systems (UAS) Frequently Asked Questions, FED. AVIATION ADMIN., https:/www.faa.gov/uas/faqs/ [perma.cc/RLZ4-FPRZ] (last modified Feb. 1, 2018, 11:26 AM).

232 U.S. DeP’t of Transp., Office of Inspector Gen., Audit Report No. AV-2017-018, FAA Lacks a Risk-Based Oversight Process for CiviL UNMANNED AIRCRAFT SYSTEMS 2 (2016), https://www.insurancejournal.com/app/uploads/2016/12/FAA-Oversight-ofUAS-Final-Report.pdf [perma.cc/X9HD-VATH]. 
The report stated:

FAA streamlined its process in 2015 for exempting civil UAS from regulatory requirements in response to increasing requests for exemptions and concerns over lengthy approval times. This enabled FAA to increase its processing rate, and the rate of exemptions granted increased over five-fold in 1 month. However, FAA's process does not verify that operators actually meet or understand the conditions and limitations of their exemptions either before or after the application is approved. Instead, FAA relies solely on information provided up front by applicants. As a result, we identified instances where exemption holders were not in compliance with their approval (e.g., flying a UAS without a required pilot's license) or did not understand certain exemption provisions (e.g., prohibited night operations). FAA also does not track exemption holders beyond the mailing address submitted during the application process. As a result, FAA has limited knowledge of where UAS actually operate and limited means to oversee those exempted operators. 233

This was preceded two years earlier by an equally critical evaluation by DOT, criticizing the FAA's work within the timetable established by Congress:

First, following many years of working with industry, FAA has not reached consensus on standards for technology that would enable UAS to detect and avoid other aircraft and ensure reliable data links between ground stations and the unmanned aircraft they control. Second, FAA has not established a regulatory framework for UAS integration, such as aircraft certification requirements, standard air traffic procedures for safely managing UAS with manned aircraft, or an adequate controller training program for managing UAS. Third, FAA is not effectively collecting and analyzing UAS safety data to identify risks. This is because FAA has not developed procedures for ensuring that all UAS safety incidents 
are reported and tracked or a process for sharing UAS safety data with the U.S. Department of Defense (DoD), the largest user of UAS. Finally, FAA is not effectively managing its oversight of UAS operations. Although FAA established a UAS Integration Office, it has not clarified lines of reporting or established clear guidance for UAS regional inspectors on authorizing and overseeing UAS operations. Until FAA addresses these barriers, UAS integration will continue to move at a slow pace, and safety risks will remain.

FAA is making some progress in meeting UAS-related provisions of the FAA Modernization and Reform Act of 2012, but the Agency is significantly behind schedule in meeting most of them, including the goal of achieving safe integration by September 2015. FAA has completed 9 of the act's 17 UAS provisions, such as selecting 6 test sites, publishing a UAS Roadmap, and developing a comprehensive plan outlining FAA's UAS plans in the near- and long-term. However, the Agency missed the statutory milestones for most of these provisions, and much work remains to fully implement them. FAA is also behind schedule in implementing the remaining eight UAS provisions. For example, FAA will not meet the August 2014 milestone for issuing a final rule on small UAS operations. FAA's delays are due to unresolved technological, regulatory, and privacy issues, which will prevent FAA from meeting Congress' September 30, 2015, deadline for achieving safe UAS integration. As a result, while it is certain that FAA will accommodate UAS operations at limited locations, it is uncertain when and if full integration of UAS into the NAS will occur. 234

234 U.S. Dep't of Transp., Office of Inspector Gen., Audit Report No. AV-2014-061, FAA FaCes Significant BarRiers to SAFEly Integrate Unmanned Aircraft Systems into the National Airspace System 2-3 (2014), https://www.oig.dot.gov/sites/default/files/FAA\%20Oversight \%20of\%20Unmanned\%20Aircraft\%20Systems\%5E6-26-14.pdf [perma.cc/CTC4-XGAX] (footnotes omitted), 
Alas, in August 2016, the FAA codified Part 107, a new mainline regulatory scheme that came into effect for civil (and thus commercial) flights of UAVs weighing under fifty-five lbs.235 Under Part 107, the person flying a drone must be at least sixteen years old and have a remote pilot certificate with a small UAS rating, or be directly supervised by someone with such a certificate. 236 Other key features of the new final rule, include the requirement that remote pilots keep their aircraft within visual line of sight, aircraft are prohibited from flying higher than 400 feet above the ground and cannot operate over people, and operations during daylight and during twilight are allowed if the drone has anti-collision lights. 237

Industry stakeholders have generally applauded Part 107, including a waiver mechanism by which some operational strictures can be loosened or avoided in appropriate circumstances. For example, pursuant to 14 C.F.R. § 107.205 a certificate of waiver (a "CoW") may, in approved circumstances based on "performance-based standards," grant an operator the right to fly at night, in Class B, C, D, \& E surface areas, beyond visual line of sight, over people, over 400 feet above the ground, and near manned aircraft. 238 By

235 The COA and " 333 " framework continues to apply to UAV weighing more than fifty-five lbs., though most small UAV operators previously issued a COA are migrating to Part 107 operations. Also, according to the FAA, pending issuance of separate rules for micro-UAV (those weighing under 0.55 lbs.), micro-UAV are governed by Part 107. Small Unmanned Aircraft Systems, 14 C.F.R. pt. 107 (2018).

236 Press Release, Fed. Aviation Admin., DOT and FAA Finalize Rules for Small Unmanned Aircraft Systems (June 21, 2016), https://www.faa.gov/news/press_releases/news_story.cfm?newsId=20515 [perma.cc/XR4M-K9WS].

237 Id.

238 To obtain a certificate of waiver (a "CoW") an applicant must submit a request containing a complete description of the proposed operation and a justification, including supporting data and documentation as necessary, that establishes that the proposed operation can safely be conducted under the terms of the requested CoW. Operation and Certification of Small Unmanned Aircraft Systems, 81 Fed. Reg. 42064, 42072 (June 28, 2016) (to be codified at 14 C.F.R. pts. 21, 43, 61, 91, 101, 107, 119, 133, 183). See also List of Regulations Subject to Waiver, 14 C.F.R. $§ 107.205$ (2018). For example, a request for a major deviation from Part 107 for an operation that 
November 29, 2017, the FAA had issued 1208 Part 107 waivers, the highest percentage (70\%) of which were for night operations, followed by operations over people (29\%), BVLOS (17\%), altitude deviation (9\%), and operations from moving vehicles (7\%).239 Still, the waiver scheme under Part 107 is not entirely satisfactory in terms of promoting and supporting innovation. The strategy of the head of AT\&T's drone program, for example, has been to keep his drones compliant with current regulations governing size and mission rather than pursuing operations that would require constant haggling over waivers. 240

In all, early policy statements, aspirational forecasts unaccompanied by rules, and cumbersome (both for regulators and the regulated) waiver processes neither reassure careful civil UAV users of a path forward nor present risk-taking operators with any compelling reason to comply with registration or certification processes, the noncompliance of which is enforced unsystematically and selectively. Indeed, the FAA's slow approach to UAV integration risked an ungovernable situation as the law failed to keep pace with the proliferation of UAVs and advances in unmanned aviation. ${ }^{241}$

takes place in a congested metropolitan area with heavy air traffic will likely require significantly more data and analysis than a request for a minor deviation for an operation that takes place in a sparsely populated area with minimal air traffic. Operation and Certification of Small Unmanned Aircraft Systems, 81 Fed. Reg. at 42072. If a CoW is granted, that certificate may include additional conditions and limitations designed to ensure that the small UAS operation can be conducted safely. Id.

239 Fed. Aviation Admin., Office of Comm., Administrator's Fact Book 15 (2017), https://www.faa.gov/news/media/2017_Administrators _Fact_Book.pdf [perma.cc/GDA4-MF85].

240 Berinato, supra note 9, at 16. See also Todd Bishop, Letter: Amazon Running Out of Patience with FAA on Drone Limits, GEekWIRE (Dec. 9, 2014 8:52 AM), https://www.geekwire.com/2014/letter-amazon-running-patiencefaa-drone-testing-limits/ [perma.cc/W974-WNVX]

241 Graham Warwick, FAA Under the Gun to Issue SUAS Rule, Aviation WK. Network (Mar. 17, 2014), http://aviationweek.com/awin/faaunder-gun-issue-suas-rule [perma.cc/K4HZ-FYWZ] ("From filming weddings and homes for sale to delivering beers to fisherman and packages at doorsteps, the FAA is struggling to stop the burgeoning commercial use of UAVs until it can get regulations governing their use in place.”). 


\section{FIGURE 3. HOBBY VS COMMERCIAL UAS OPERATIONS DISTINGUISHED 242}

\begin{tabular}{|c|c|c|}
\hline & Fly for Fun & Fly for Work \\
\hline $\begin{array}{l}\text { Pilot } \\
\text { Requirements }\end{array}$ & No pilot requirements & $\begin{array}{l}\text { Must have Remote Pilot } \\
\text { Airman Certificate } \\
\text { Must be } 16 \text { years old } \\
\text { Must pass TSA vetting }\end{array}$ \\
\hline $\begin{array}{l}\text { Aircraft } \\
\text { Requirements }\end{array}$ & $\begin{array}{l}\text { Must be registered if over } 0.55 \\
\text { lbs. }\end{array}$ & $\begin{array}{l}\text { Must be less than } 55 \text { lbs. } \\
\text { Must be registered if over } \\
0.55 \text { lbs. (online) } \\
\text { Must undergo pre-flight } \\
\text { check to ensure UAS is in } \\
\text { condition for safe operation }\end{array}$ \\
\hline $\begin{array}{l}\text { Location } \\
\text { Requirements }\end{array}$ & $\begin{array}{l}5 \text { miles from airports without } \\
\text { prior notificaiton to airport and } \\
\text { air traffic control }\end{array}$ & Class G airspace* \\
\hline $\begin{array}{l}\text { Operating } \\
\text { Rules }\end{array}$ & $\begin{array}{l}\text { Must ALWAYS yield right of } \\
\text { way to manned aircraft } \\
\text { Must keep the aircraft in sight } \\
\text { (visual line-of-sight) } \\
\text { UAS must be under } 55 \text { lbs. } \\
\text { Must follow community-based } \\
\text { safety guidelines } \\
\text { Must notify airport and air } \\
\text { traffic control tower before } \\
\text { flying within } 5 \text { miles of an } \\
\text { airport }\end{array}$ & $\begin{array}{l}\text { Must keep the aircraft in } \\
\text { sight (visual line-of-sight)* } \\
\text { Must fly under } 400 \text { feet*}^{*} \\
\text { Must fly during the day* } \\
\text { Must fly at or below } 100 \\
\text { mph* } \\
\text { Must yield right of way to } \\
\text { manned aircraft* } \\
\text { Must NOT fly over people* } \\
\text { Must NOT fly from a } \\
\text { moving vehicle* }\end{array}$ \\
\hline $\begin{array}{l}\text { Example } \\
\text { Applications }\end{array}$ & $\begin{array}{l}\text { Educational or recreational } \\
\text { flying only }\end{array}$ & $\begin{array}{l}\text { Flying for commercial use } \\
\text { (e.g. providing aerial } \\
\text { surveying or photography } \\
\text { services) } \\
\text { Flying incidental to a } \\
\text { business (e.g. doing roof } \\
\text { inspectiosn or real estate } \\
\text { photography) }\end{array}$ \\
\hline $\begin{array}{l}\text { Legal or } \\
\text { Regulatory } \\
\text { Basis }\end{array}$ & $\begin{array}{l}\text { Public Law 112-95, Section } \\
\text { 336-Special Rule for Model } \\
\text { Aircraft } \\
\text { FAA Interpretation of the } \\
\text { Special Rule for Model Aircraft }\end{array}$ & $\begin{array}{l}\text { Title } 14 \text { of the Code of } \\
\text { Federal Regulation ( } 14 \\
\text { CFR) Part } 107\end{array}$ \\
\hline
\end{tabular}

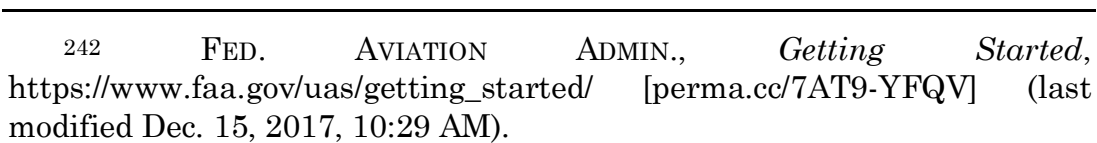




\section{B. Regulatory Enforcement}

As detailed in Section III.A, supra, in situations in which the FAA had authority to act and did act with respect to commercial drones, it failed to meet statutory milestones that Congress wrote into law. This left the private sector effectively grounded and without clear regulatory direction. The pace and timeliness of FAA decision-making was a problem. This Section presents a different and more substantive problem: how the FAA has exerted its authority. That is, where the FAA has acted (timely or not), it has exercised its power in ways that apparently conflicted with prior agency practice and policy and arrested the innovation environment.

The aftermath of the flight of Raphael "Trappy" Pirker's unmanned aircraft—a Ritewing Zephyr_on October 17, 2011 best illustrates the intensity and reasoning of the FAA in asserting its authority in the drone space. Pirker flew a model airplane in a series of maneuvers around the University of Virginia campus in Charlottesville, Virginia, allegedly at altitudes ranging from the extremely low level of ten feet above ground level up to 1500 feet.243 According to the FAA, he operated the airplane "directly towards an individual standing on a ... sidewalk causing the individual to take immediate evasive maneuvers so as to avoid being struck by [the] aircraft." 244 Then, he flew "through a . . . tunnel containing moving vehicles ... under a crane ... below tree top level over a tree lined walkway ... under an elevated pedestrian walkway ... and within approximately 100 feet of an active heliport." 245 Consequently, the FAA fined Pirker $\$ 10,000$ under 14 C.F.R. 91.13(a) for operating an "aircraft in a careless or reckless manner so as to endanger the life or property of another."246

243 Raphael Pirker, N.T.S.B. Order No. EA-5730, 2014 WL 8095629, at *2 (Nov. 17, 2014) (final admin. review).

244 Id.

245 Id

246 Brief for Appellant at 2, Raphael Pirker, N.T.S.B. Order No. EA5730, 2014 WL 8095629 (Nov. 17, 2014) (quoting 14 C.F.R. § 91.13(a) (2018)). See Kelsey D. Atherton, Judge Strikes Down FAA's Ban On 
Pirker challenged the penalty, arguing that the FAA did not have legal authority to regulate model aircraft flight operations such as his.247 On the other hand, the FAA argued that it had the power to regulate all "aircraft," and that "model aircraft" fell within the scope of the term "aircraft."248 Pirker's glider, the FAA contended, was an "aircraft" and was operated for compensation in that payment was received for video and photographs taken during the flight. 249 Judge Patrick Geraghty of the National Transportation Safety Board ("NTSB"), sitting as the Administrative Law Judge ("ALJ"), disagreed, reasoning that the FAA had historically considered "aircraft" and "model aircraft" as two different aircraft.250 In fact, the FAA had modified the term "aircraft" by prefixing the word "model" in its policies to distinguish one device or contrivance from another. ${ }^{251}$ Notwithstanding the FAA's argument that it left unchanged the traditional definition of "aircraft" as any "device that is used or intended to be used for flight in the air,"252 the ALJ concluded that the FAA's power to regulate "aircraft" did not extend to the regulation of "model aircraft." 253 To believe otherwise would be to entertain the "risible argument that a flight in the air of, e.g., a paper aircraft, or a toy balsa wood glider, could subject the 'operator' to the regulatory provisions of [the] FAA," the ALJ wrote. ${ }^{254}$

Critically, the ALJ also noticed that the the FAA had not formally enacted any rule allowing it to regulate "model"

\footnotetext{
Commercial Drones, PopUlar SCI. (Mar. 7, 2014), http://www.popsci.com/article/technology/judge-strikes-down-faas-bancommercial-drones [perma.cc/HL2H-QY6M].

247 Brief for Appellant at 3, Raphael. Pirker, N.T.S.B. Order No. EA5730, 2014 WL 8095629 (Nov. 17, 2014).

248 Decisional Order at 3, Raphael Pirker, N.T.S.B. Order No. EA-5730, 2014 WL 8095629 (Nov. 17, 2014).

249 Decisional Order Attachment 1 at 1, Raphael Pirker, N.T.S.B. Order No. EA-5730, 2014 WL 8095629 (Nov. 17, 2014).

250 Decisional Order at 8, Raphael Pirker, N.T.S.B. Order No. EA-5730, 2014 WL 8095629 (Nov. 17, 2014).

251 Id. at 3.

252 Id.

253 Id. at 4.

254 Id. at 3.
} 
aircraft as "aircraft," and so it could not apply long-standing laws applicable to aircraft to Pirker's model airplane for enforcement or litigation purposes. That is,

[The FAA] has not issued an enforceable [Federal Aviation Regulation ("FAR")] regulatory rule governing model aircraft operation; has historically exempted model aircraft from the statutory FAR definitions of 'aircraft' by relegating model aircraft operations to voluntary compliance with [existing FAA guidance] .... [Thus, Pirker's] model aircraft was not subject to FAR regulation and enforcement. 255

The ALJ also highlighted the fact that the FAA did not follow the proper rulemaking procedures for enacting valid UAV regulations. 256 While it had published various notices and policy statements with respect to UAVs, it had done so for internal purposes and not for purposes applicable to the general public. 257 To create a valid rule for UAV operation the FAA should have published a Notice of Proposed Rulemaking without which "there was no enforceable FAA rule or FAR Regulation applicable to model aircraft or for classifying model aircraft as an UAS." 258

Approximately one month after the ALJ's order, the FAA appealed to the full NTSB, 259 announcing in a press release that the appeal was necessary because "this decision could impact the safe operation of the national airspace and the safety of people and property on the ground." 260 The FAA attacked the "ALJ's reasoning for finding that a Ritewing Zepher power glider is not an aircraft under the statutory and

$255 I d$. at 4.

256 Id.

257 Id. at 5 (citing Syncor Int'l Corp., 56 F.3d 592, 595 (5th Cir. 1995)) (explaining that an administrative body's policy guidance cannot be binding unless it has been released to the general public for comment).

$258 \mathrm{Id}$.

259 See Brief for Appellant at 1, Raphael Pirker, N.T.S.B. Order No. EA5730, 2014 WL 8095629 (Nov. 17, 2014).

260 Press Release, Fed. Aviation Admin., FAA Statement (Mar. 7, 2014), http://www.faa.gov/news/press_releases/news_story.cfm?newsId $=15894$ [perma.cc/5HG3-QCSD]. 
regulatory definitions of the word 'aircraft' [as] both illogical and deeply flawed." 261 The FAA also emphasized its extraordinary concurrent roles of author, interpreter, and enforcer of its own rules, noting that the "FAA stands in a better place than [the ALJ] to know both what the statutory and regulatory definitions of the word 'aircraft' mean and the parameters of its authority to enforce its own regulations."262 The FAA ultimately won the case as the NTSB ruled that Pirker's UAV fell within the plain language of aircraft under 49 U.S.C. § 40102(6): "any contrivance invented, used, or designed to navigate, or fly in, the air." 263 Moreover, the NTSB ruled, "the statutory and regulatory definitions, as well as Advisory Circular 91-57, and FAA Notice 07-01, contain no express exclusion for unmanned or model aircraft."264

Since Pirker, the FAA has reported issuing slightly less than two dozen civil penalties to drone operators, with fines generally ranging between $\$ 400$ and $\$ 5500$ (with one outlier at $\$ 1.9$ million). Enforcement has concentrated in New York, Washington, D.C., and Boston 265 - though no one seems to have been fined for flying a drone commercially.266 The FAA

261 Brief for Appellant at 5, Raphael Pirker, N.T.S.B. Order No. EA5730, 2014 WL 8095629 (Nov. 17, 2014).

262 Id. (citing Chevron U.S.A., Inc. v. Natural Res. Def. Council, 467 U.S. 837, 842 (1984) (explaining that an agency is entitled to substantial deference in interpreting its own rules)).

263 Raphael Pirker, N.T.S.B. Order No. EA-5730, 2014 WL 8095629 (Nov. 17, 2014). See John Goglia, NTSB Overturns Pirker Case: Finds for FAA that Drones are Aircraft Subject to Its Rules, ForBes (Nov. 18, 2014, 9:57 AM), http://www.forbes.com/sites/johngoglia/2014/11/18/ntsboverturns-pirker-finds-for-faa-that-drones-are-aircraft-subject-to-its-rules/ ("Mr. Pirker can appeal this case to the Court of Appeals. Since there is no chance of FAA drone rules being published in the near future, it is now up to Congress to determine whether it wants every model aircraft regardless of size to be regulated by the FAA's rules for manned aircraft.").

264 Pirker, 2014 WL 8095629, at *7.

265 Jason Koebler, The FAA Gave Us a List of Every Drone Pilot Who Has Ever Been Fined, MotherboARD (June 1, 2016, 2:20 PM), http://motherboard.vice.com/read/faa-drone-fines.

266 Jason Koebler, The FAA Has Never Fined Anyone For Flying a Drone Commercially, Motherboard (June 1, 2016, 2:30 PM), 
has predicated these fines on the very same catch-all regulation-14 C.F.R. § 91.13-applied in Pirker, which prohibits flying in a "careless or reckless manner." Highlights of FAA UAV enforcement follow:

- September 30, 2013. David Zablidowski was fined $\$ 2,200$ (settled for $\$ 400$ ) for flying in Manhattan, landing on the ground 20 feet from a person. (This was the first hobbyist ever fined for flying a drone.)

- July 7, 2014. Wilkens Mendoza was fined $\$ 1,100$ and arrested by the New York Policy Department for flying a drone near the George Washington Bridge. (The fine was later withdrawn.)

- January 26, 2015. Shawn Usman, a government employee, was fined $\$ 5,500$ for crashing his drone into a tree on the White House lawn.

- May 14, 2015. Ryan MacDonald was fined $\$ 4,400$ after flying a drone in Lafayette Park near the White House. The FAA claimed that the secret service "cleared the entire north side of the White House of people ... due to your operation of the aircraft."

- May 16, 2015. Xizmo Media Productions was fined $\$ 18,700$ (settled for $\$ 5,500$, in monthly installments of $\$ 222.22$ until June 2017) for flying an unregistered drone recklessly in connection with shooting footage of Fordham University's 2015 commencement ceremony.

- July 5, 2015. Jorge Lubo was fined $\$ 1,100$ in connection with flight of his Parrot Bebop, which crashed into a United States Coast Guard vehicle.

- September 17, 2015. Adam Rupeka was fined $\$ 1,100$ for crashing his drone into the New York State Capitol building.

- September 3, 2015. Daniel Verley was fined \$2,200 (settled for $\$ 1,320$ ) for flying a drone above the U.S. Open, crashing 70 feet from the tennis court.

- October 2015. Chicago-based SkyPan was fined $\$ 1.9$ million - the largest drone fine ever levied-

http://motherboard.vice.com/read/the-faa-has-never-fined-anyone-forflying-a-drone-commercially. 
in connection with repeated drone flights near high rises in restricted airspace around the nation. The matter was settled for $\$ 200,000$.

The chief takeaway of the Pirker decision may not be the final decision reached, but how the FAA failed in many ways to serve their constituents. In particular, stakeholders in emerging commercial sectors are not well-served when regulators-even if ultimately successful-express their positions as defendants in administrative proceedings rather than through formal, proper (and, in the FAA's case, congressionally-mandated) rulemaking. Indeed, the FAA's appeal in Pirker itself created uncertainty. On the one hand, the ALJ had confirmed that the FAA had not enacted any UAV-specific regulations-a situation that seemingly should have allowed UAV operators to proceed until a definite set of regulations were enacted. (The ALJ's decision was stayed pending the FAA's appeal.) On the other hand, the FAA had produced guidance that put the UAV community on notice of its authority to permit or restrict flight of arguably. This left UAV operators to decide for themselves how to proceed-fly with the expectation that the ALJ's decision would be affirmed, or stay on the ground while other commercial operators brushed aside the FAA's appeal and gained market share.267 This situation endured for almost a quarter of 2014 . And, while the FAA perhaps vindicated its position as the dominant authority on all aircraft-related issues, it did so at the expense of effectuating the FMRA's directive that the FAA create and implement rules integrating UAVs into the NAS. 268

267 The FAA is blameless for this circumstance in part because uncertainty is expected when a lower court rules adversely to any agency interpretation. But, what was surprising about Pirker was the verve with which the FAA litigated and asserted its power to regulate commercial drones in light of its failure to formalize any rules or guidance that did anything more than disallow any ground operators.

268 See, e.g., Mike Masnick, FAA Settles Key Case Over Commercial Drone Use . . . Leaves the Rest of Us with No Rules At All, TECHDIRT (Jan. 23, 2015, 1:37 PM), https://www.techdirt.com/articles/20150122/ 17333929785/faa-settles-key-case-over-commercial-drone-use-leaves-restus-with-no-rules-all.shtml [perma.cc/TBU4-FM7A] (reporting that Mr. 


\section{Regulatory Decisions with Incomplete Data}

In addition to the foregoing criticisms of the FAA-that the agency used its limited resources to reverse engineer existing aviation rules to fit the circumstances in Pirker for enforcement purposes rather than to timely enact new UAV rules-the information on which the FAA has effected its decisions respecting UAVs has also drawn disapproval.

In fairness, with the FAA projecting 7 million drones in the national airspace by 2020,269 incorporating unmanned aerial operations into an ecosystem originally designed for manned flight is not an easy job. Complicating matters is the fact that FAA resources are as limited as any other federal agency, if not more so. The FAA had no employees or offices dedicated to the issue of UAVs until only recently, with the formation of its Unmanned Aircraft Program Office occurring in 2016. And, the Air Traffic Organization ("ATO"), the operational arm of the FAA, is already responsible for providing safe and efficient air navigation services to 29.4 million square miles of airspace-representing more than $17 \%$ of the world's airspace. 270 Adding autonomous and optionally-piloted remote-control airplanes into this mix presents a formidable regulatory ask. A general aviation airport manager made the point by expressing confusion why the FAA restricted him from refusing to allow a UAV operator to fly in critical spaces near his airport when the FAA itself was ill-equipped to deter and punish dangerous behavior:

I have no right to decline UAS operations at the approach-end of a runway. I have to give way. When the [drone operator is] bad, I advise [the FAA's] flight

Pirker agreed to pay $\$ 1100$ to the FAA, without an admission of wrongdoing, in full and final settlement of the enforcement action against him).

269 Press Release, Fed. Aviation Admin., FAA Releases 2016 to 2036 Aerospace Forecast, https://www.faa.gov/news/updates/?newsId=85227 \&cid=TW414 [perma.cc/D532-FNDB] (last modified Mar. 24, 2016, 12:!0 PM).

270 Air Traffic Organization, Fed. Aviation Admin., https://www.faa.gov/about/office_org/headquarters_offices/ato/ [perma.cc/RC6F-76JL] (last modified Dec. 5, 2017, 10:25 AM). 
standards [personnel]. Which is an idle threat because they only have 3 people there who have responsibility for an area the size of West Virginia and some users are very well aware of it. 271

Unsurprisingly, the FAA has approached civil UAVs with precautionary principle-based thinking, i.e., "the belief that new innovations should be curtailed until their developers can prove that they will not cause any harms to individuals, groups, specific entities, or various existing laws, norms, or traditions." 272 However, the actual number of potential conflicts between manned and unmanned airplanes near airports is wanting, though anecdotal evidence is not hard to find worldwide. 273 For example, in March 2015, the United Arab Emirates Department of Economic Development banned the use and sale of recreational drones after one flew too close to critical flight paths and forced the suspension of all flights at Dubai International Airport.274 In 2016, Dubai's airportthe third busiest in the world-was forced to shut down three separate times because of unauthorized drone activity, with the most recent shutdown requiring the diversion of flights and the closing of the airport for ninety minutes at a cost of $\$ 1$ million a minute. 275 Dubai's experience is not isolated: Polish aviation authorities took steps to revise their drone regulations after a drone nearly collided with a commercial jetliner at Warsaw Chopin Airport.276 In the United States,

271 UAS and Airports: Survey, RAVICH LAW FIRM, PLLC (2016-2017) (on file with author).

272 Thierer, supra note 20, at 39.

273 See, e.g., Gareth Corfield, supra note 19 ("Although the near-miss was reported to police, a search of the area revealed no trace of the drone or its operator.").

274 Anwar Ahmad, Sale of Drones Banned in Abu Dhabi, National (Mar. 11, 2015, 4:00 AM), http://www.thenational.ae/uae/sale-ofrecreational-drones-banned-in-abu-dhabi [perma.cc/B3AX-7E56].

275 Zahraa Alkhalisi, Dubai Deploys a 'Drone Hunter' to Keep Its Airport

Open, CNN: TECH (Nov. 4, 2016, 6:24 AM), http://money.cnn.com/2016/11/04/technology/dubai-airport-drone-hunter/ [perma.cc/AB39-E7F2].

276 Safe Sky-Regulations of Drones in Poland, URZAd Lotnictwa CrwilneGo (Oct. 2, 2015), http://www.ulc.gov.pl/en/270-english/current- 
meanwhile, vendors Brookstone and Hudson News removed UASs from their airport store shelves after New York and New Jersey transportation authorities demanded that they stop offering the merchandise for sale. 277 And, most recently, on November 28, 2017, a research team from the Alliance for System Safety of UAS through Research Excellence ("ASSURE") released a report detailing how drones colliding with large manned aircraft could cause more structural damage than birds of the same weight for a given impact speed-a finding that will assist the FAA in developing operational and collision risk mitigation requirements for drones. 278

In this context, the FAA's initial reaction to the drone economy-a ban on all civil (e.g., non-government) and commercial operations-reflected a policy decision that the seriousness of an accident or incident involving a drone outweighed even the small probability of such an event occurring. 279 This reasoning was no doubt informed by reports about drones conflicting and nearly colliding with passenger jets and other aviation traffic around airports. In fact, in 2015, the FAA released a report of 650 "possible encounters with unmanned aircraft" between November 2014 and August 2015 - with drone "sightings" estimated as high as 100 a month in 2015-five times as many as one year earlier.

information/3806-safe-sky-regulations-on-flying-drones-in-poland [perma.cc/8JMY-5EUU].

277 Airport Stores Agree to Stop Selling Drones After Plea from Port Authority, FAsT COMPANY (Aug. 20, 2015), https://www.fastcompany.com/3050155/fast-feed/airport-stores-agree-tostop-selling-drones-after-plea-from-port-authority [perma.cc/S3Z5-4TTK].

278 Researchers Release Report on Drone Airborne Collisions, FED. Aviation ADMIN., https:/www.faa.gov/news/updates/?newsId=89246 [perma.cc/HXK8-8GXM] (last modified Nov. 28, 2017, 12:52 PM).

279 Manufacturers and safety-conscious drone operators themselves believe that just one tragedy involving a reckless or careless drone operator and a commercial jet would undo the progress made by responsible drone builders and users and doom the development of any and all civil and commercial drone industry from a regulatory perspective. See, e.g., UAS Issues and Integration Conference, AM. ASS'N AIRPORT EXECUTIVES, https://www.aaae.org/AAAE/AAAEMemberResponsive/Events/2016/11/161 107/CCO_Master.aspx (comments of various panelists and attendees). 
But, industry observers have challenged as incomplete the data underlying the ban the FAA imposed on civil drones. Reported drone encounters occurred above 3,000 feet-well above the 500-foot ceiling established for commercial UAS and 400 feet recommended for model aircraft. This reality prompted an Aviation Week and Space Technology editorial to assert that, "[t]he FAA did itself no favors by releasing a list of 650 'possible encounters with unmanned aircraft' reported between November 2014 and August 2015. This mixes pilot sightings close to airports, where the threat is highest, with passing encounters and reports from air traffic controllers and the public. It is good for grabbing headlines, but not for defining dangers." 280

This criticism has persisted. The Inspector General of DOT wrote a 2016 audit that was critical of the FAA for failing to address the risk of drones in a concerted way:

While FAA has taken some steps to advance UAS technology, the Agency has not established a riskbased safety oversight process for civil UAS operations-a key tool for focusing resources on a range of emerging risks. Moreover, FAA safety inspectors have received only limited UAS-related training and guidance. For example, as of April 2016, there were no formal, instructor-led training courses and only two outdated online courses available to inspectors focused on UAS technology.

In addition, FAA field offices, which are responsible for oversight, do not receive sufficient information regarding UAS operators-such as where or when most UAS will be operating in their jurisdiction-from Agency Headquarters, hindering their ability to provide proactive oversight. At the same time, reports of UAS sightings to FAA primarily from pilots have risen to over 100 per month. Despite this increase in

280 Better Data Needed on Risks Small UAS Pose to Air Traffic, 177 Aviation WK. \& Space Tech. 1 (2015); see also Craig Whitlock, FAA Records Detail Hundreds of Close Calls Between Airplanes and Drones, Wash. Post (Aug. 20, 2015), https://www.washingtonpost.com/world/nationalsecurity/faa-records-detail-hundreds-of-close-calls-between-airplanes-anddrones/2015/08/20/5ef812ae-4737-11e5-846d-02792f854297_story.html. 
reported UAS events, FAA's enforcement actions for operators who violate UAS requirements have been limited, in part because FAA thus far has prioritized operator education over enforcement. In the absence of a risk-based oversight system, FAA inspectors respond primarily to incidents only after they are reported. FAA also lacks a robust data reporting and tracking system for UAS activity, and the information available is difficult to analyze and collected in a fragmented manner throughout the Agency.

For example, one FAA office received reports indicating that an approved UAS operator was flying regularly at night — outside of exemption limitationsbut due to a lack of routine analysis, this office did not provide the information to the field for further investigation until an FAA inspector requested it 4 months later in response to a complaint. As a result, FAA is currently restricted to a reactive approach to UAS oversight, rather than proactively identifying and mitigating risks with a rapidly advancing technology. 281

In fact, the FAA is struggling to keep up with the risk that recreational drones pose. Recently, near and around airports, reports of safety incidents involving civilian drones surged to an average of 250 a month by October 2017, leading to a federal "emergency." In fact, in September, 2017, the NTSB confirmed a midair collision involving a drone and a manned military aircraft, a UH-60 Black Hawk helicopter that was patrolling New York Harbor during the United Nations General Assembly.282 Taking these events together, the FAA

281 U.S. DEP'T OF TransP., supra note 232, at 2-3.

282 See, e.g., Jim Moore, Drone Pilot Provides Data from Black Hack Midair, AOPA (Oct. 5, 2017), https://www.aopa.org/news-and-media/allnews/2017/october/05/drone-pilot-provides-data-from-black-hawk-midair [perma.cc/PFX4-QKBS]; Jim Moore, FAA Seeks 'Emergency' Action on Drones, AOPA (Oct. 16, 2017), https://www.aopa.org/news-and-media/allnews/2017/october/16/faa-seeks-emergency-action-on-drones

[perma.cc/PZ3M-ZVNU] ("The helicopter landed safely despite main rotor damage, and a piece of the drone was recovered from inside the helicopter that led investigators to the operator with help from drone maker DJI. The area where the Sept. 21 collision took place does not appear to be within an 
published a notice in the Federal Register on October 11, 2017 , to request authority on an emergency basis from the White House Office of Management and Budget to put electronic authorization of drone flights in controlled airspace on a fast track. 283 The agency's 90-day processing time for approvals has led to a sharp increase of "non-compliant" operations:

Since the promulgation of part 107, the FAA has received an extremely high volume of airspace authorization requests for UAS operations. From September 2016 to July 2017 the Agency received 20,566 authorization requests. Of these, the Agency has processed 14,334 and continues to have over 6,000 authorizations in the processing queue. Requests have steadily increased over time, and the FAA expects the queue will exceed 25,000 pending authorizations within the next 6 months. The volume of these authorization requests has dramatically increased the time between submission and approval of those authorization requests. Currently, airspace authorization requests may be in queue sixty to ninety days before receiving a response. The time necessary to process these requests has resulted in an increase in safety reports due to noncompliant operations. Today there are an average of 250 safety reports a month, or approximately 1,500 over a six-month period, associated with a potential risk of an incident between manned aircraft and a UAS. 284

The FAA had expected to take until the end of the year to automate airspace authorization requests through the Low Altitude Authorization and Notification Capability ("LAANC") system, but "the pressing safety consideration of

area where a drone flight could have been authorized, given the tightly controlled New York Class B airspace and the presence of flight restrictions to protect the U.N. General Assembly. The U.S. Army, NTSB, and FAA are all investigating, and no sanctions have been announced against the pilot, who is cooperating with the investigation, NTSB officials said.").

283 See FAA Seeks 'Emergency' Action on Drones, supra note 282.

284 Request for Emergency Processing of Collection of Information by the Office of Management and Budget, 82 Fed. Reg. 47289 (Oct. 11, 2017). 
reducing safety reports due to non-compliant UAS operations [apparently means] the FAA cannot wait the normal 90 days of public comment," the agency FAA advised.285 In the final analysis, the FAA's approach to drone safety has had a certain ad hoc quality to it that is difficult to reconcile with the time it has had to plan and budget for foreseeable risks.

\section{Regulatory Overreach: Chevron Deference}

To this point, FAA UAV policy has been criticized for its timeliness, its apparent conflict with prior agency practice, and at times its lack of a complete evidentiary basis. More concerning than these items-and perhaps most concerning generally -is the agency's regulatory overreach. For example, a federal appeals court in Washington, D.C. recently struck down a rule requiring recreational drone users to register their devices with the FAA.286

The FAA rolled out its registration requirement in late 2015 as a safety measure designed to protect the skies from irresponsible and uninformed flyers of small drones. The new regulatory regime required both commercial and recreational drone operators to provide contact information, pay a $\$ 5$ registration fee, and obtain a unique FAA-issued identifier number to affix to drone before flying. 287 Failure to register carried civil and criminal penalties, including up to three years' imprisonment. 288

285 Id. The FAA characterized the Low Altitude Authorization and Notification Capability system as "vital to the safety of the National Airspace System because it would (1) encourage compliance with 14 CFR 107.41 by speeding up the time to process authorization requests (2) reduce distraction of controllers working in the Tower, and (3) increase public access and capacity of the system to grant authorizations." Id. The FAA further estimated that at least a thirty percent reduction in noncompliant operations would result in 450 fewer safety reports over the next six months. Id.

286 See Taylor v. Huerta, 856 F.3d 1089 (D.C. Cir. 2017).

287 Aircraft Registry-Aircraft Registration: Unmanned Aircraft (UA), FED. AVIATION ADMIN., https://www.faa.gov/licenses_certificates/aircraft_ certification/aircraft_registry/UA/ [perma.cc/6N8M-CC9K] (last modified Mar. 8, 2018, 5:47 PM).

288 Taylor, 856 F.3d at 1092. 
While close to 800,000 drone operators registered, airplane hobbyists have objected to the Registration Rule since its inception. 289 The rule, after all, was borne out of a rushed attempt to manage the anticipated sale of millions of new drones weighing about half a pound or more during the holiday season. In November 2015, the FAA convened an industry working group to make formal recommendations about which "aircraft should be exempt from registration due to a low safety risk, including toys and certain other small [drones]." 290 Members of the registration task force had a mere 30 days to develop the regulatory platform, which the FAA proceeded to formalize in a final Registration Rule in December 2015 on an emergency basis. 291

The FAA never explained why or how a mandatory registration rule extended to hobby drones flown in backyards below the national airspace (approximately 500 feet) enhanced public safety. Although the FAA released a list of 650 "possible encounters with unmanned aircraft" between November 2014 and August 2015, the agency provided no data to differentiate the real danger of small drones flying near airports from passing encounters and reports from the public. What is more, the FAA never explained how a registration requirement for model aircraft would accomplish (or has since accomplished) the overarching objective of identifying, deterring, and taking enforcement action against unscrupulous and anonymous drone operators who have no incentive to voluntarily comply with the law.

But the most significant objection to the Registration Rule was the legality of the rule itself as applied to hobby drones. That was the key issue in Taylor v. Huerta, a case brought by

289 Tony Romm, Turns Out, You're Going to Have to Register Your Small Drones with the U.S. Government After All, RECoDE (Dec. 12, 2017, 10:13 AM), https://www.recode.net/2017/12/12/16766554/us-congresstrump-drone-registration-faa [perma.cc/88MA-ZYKE].

290 David Esler, And Now a Few Words from Your FAA, Aviation Wk. NETwORK (Dec. 28, 2015), http://aviationweek.com/bca/and-now-few-wordsyour-faa [perma.cc/U2CW-YRYZ].

291 Press Release, Fed. Aviation Admin., FAA Announces Small UAS Registration Rule (Dec. 14, 2015), https://www.faa.gov/news/ press_releases/news_story.cfm?newsId=19856 [perma.cc/65TB-6RLF]. 
a Maryland lawyer who argued that the FAA had no authority to create the Registration Rule and compel him to register his hobby airplane. 292 His argument was based on a law Congress enacted in 2012, the FAA Modernization and Reform Act (the "FMRA"), which explicitly prohibits the FAA from creating "any rule or regulation regarding a model aircraft."293

Despite the FMRA's clear language, the FAA insisted that its Registration Rule was not a new rule or one that conflicted with the Act, but instead was a continuation of a 1920s-era rule requiring the registration of manned aircraft. Therefore, the FAA argued, the Registration Rule was as an exercise of its discretion of a pre-existing authority to "build a culture of accountability and responsibility."294 However, the FAA had never interpreted its registration requirement to apply to the model aircraft community, which has operated in accordance with a community-based set of safety guidelines under the auspices of a nationwide organization, the Academy of Model Aeronautics since 1936.

The FAA's arguments might have found support under a 1984 decision by the U.S. Supreme Court, Chevron U.S.A., Inc. $v$. Natural Resources Defense Council, Inc., by which courts defer to agency expertise, judgment, and interpretation. 295 But, perhaps mindful of Justice Neil Gorsuch's description of Chevron as "a judge-made doctrine for the abdication of the judicial duty," the three-judge panel of the U.S. Court of Appeals for the D.C. Circuit in Taylor did not defer to the FAA as the judge, jury, and enforcer of its own rules. ${ }^{296}$ Instead, the court did what the Constitution qualifies

292 See generally Taylor, 856 F.3d. 1089.

293 FAA Modernization and Reform Act of 2012, Pub. L. 112-95, § 336(a), 126 Stat. 11 (2012).

294 Taylor, 856 F.3d at 1092. See Press Release, Fed. Aviation Admin., U.S. Transportation Secretary Anthony Foxx Announces Unmanned Aircraft Registration Requirement (Oct. 19, 2015), https://www.faa.gov/news/press_releases/news_story.cfm?newsId=19594 [perma.cc/725J-D76Q].

295467 U.S. 837 (1984).

296 Jonathan H. Adler, Should Chevron be Reconsidered? A Federal Judge Thinks So., WASH. Post. (Aug. 24, 2016), https://www.washingtonpost.com/news/volokh-conspiracy/wp/2016/08/24/ 
only courts to do: to say what the law is, and to interpret the text and structure of a statue enacted by Congress.

As Circuit Judge Brett Kavanaugh wrote in the Taylor court's unanimous opinion, deciding the case was easy: "Statutory interpretation does not get much simpler."297 The Registration Rule was unlawful as applied to model aircraft, the court noted, because it was an attempt by an administrative agency to make a new rule despite Congress' express prohibition against the promulgation of a "rule or regulation regarding a model aircraft." 298 The court was blunt in addressing the FAA's strained position, stating at oral argument: "You're just making stuff up; that's not what the statute says." 299

In reaching its decision, the Taylor court not only confined regulators to their explicit legal authority, but it also declined the Chevron invitation to substitute its own judgment for that of Congress. In fact, the court noted that "Congress is of course always free to repeal or amend its 2012 prohibition on FAA rules regarding model aircraft. Perhaps Congress should do so. Perhaps not." 300 That is, it is not for the court to say, but neither is it for the FAA.

The Taylor case provides an important example of how well (or not) the law adapts to technological innovations in the drone age. And, in a broader context, by carefully navigating between the Scylla and Charybdis of judicial deference and overreach, the Taylor court demonstrated how traditional eighteenth century constitutional doctrines of separation of powers and judicial restraint remain relevant for reigning in the modern regulatory state. That was until December 2017,

should-chevron-be-reconsidered-a-federal-judge-thinks-so/ [perma.cc/7A4BS3YY].

297 Taylor, 856 F.3d at 1092.

$298 \mathrm{Id}$

299 Oral Argument, Taylor v. Huerta, 856 F.3d 1089 (D.C. Cir. 2017), https://www.cadc.uscourts.gov/recordings/recordings2017.nsf/469F0B57ED A3C53A852580E300577ED7/\$file/15-1495.mp3.

300 Taylor, 856 F.3d at 1093. 
when the drone registration rule was actually reinstated as part of the National Defense Authorization Act.301

\section{CONCLUSION}

Drones epitomize the IoT with their "smart" properties and untold-number of applications in the leisure, prosumer, and commercial markets, operating at the convergence of novel legal, business, and technological issues. Commercial drones, in particular, offer profound economic benefits. But these "benefits may not come about if preemptive, precautionary policy interventions limit new innovation opportunities." 302

This Article has shown defects in ex-ante policymaking in the specific context of UAVs. It has detailed four examples of how regulators have impeded the adoption of commercial drones through precautionary principle-based policymaking based on ephemeral fears and stringent prophylactic restrictions, including untimely rulemaking masquerading as deliberation and caution; aggressive enforcement arguably at odds with historic policy guidance; regulatory decisions made with incomplete data; and overreach. While the FAA has ultimately codified an initial set of uniform, national commercial UAV rules that broadly provide a pathway for some commercial UAV operations, it has left some of the potentially most profitable types of operations (e.g., night operations, beyond visual line of sight, operations over people) to a case-by-case waiver process. This waiver process may be unnecessarily paternalistic of firms that are self-incentivized and self-motivated to fly competently and safely. Indeed, a system of waivers, "in itself creates the prospect of writing

301 See e.g., Brian Heater, Trump Signs Bill Reinstating the FAA's Drone Registration Requirement, TECHCRUNCH (Dec. 12, 2017), https://techcrunch.com/2017/12/12/trump-signs-bill-reinstating-the-faasdrone-registration-requirement/ [perma.cc/S9TL-9YFK] ("The reinstated rules were one small piece of the $\$ 700$ billion National Defense Authorization Act, about which the president reportedly said, 'We need our military, it's gotta be perfecto.' Likely the bit about drone registration didn't even register a blip on the president's radar.”).

302 Thierer, supra note 20, at 117. 
policy through a series of exemptions, which would reflect a certain ad hocness rather than purposeful design." 303

To be fair, regulators are drinking from a firehose, as eighteenth-century common law conceptions of privacy and private property rights do not fit neatly into the information age and could not have anticipated a projected 7 million drones by 2020. Moreover, not to be lost in the discussion of drones as data devices is the actual safety risk that autonomous, automated, and optionally-piloted small airplanes pose to people and property at low altitudes and in the national airspace system originally designed for manned assets. As one Economist article synthesized:

Moving bits around the internet is one thing; moving atoms around in the real world is something else entirely. In the two decades of the internet era, many world-changing technologies-web-publishing, filesharing, online auctions, internet telephony, virtual currencies, ride-hailing-have raised new legal and regulatory questions. In each case, regulators had to work out the rules after the event: figuring out how libel law applies to the web, banning the sale of Nazi memorabilia, deciding whether Bitcoin is a currency, determining whether Uber drivers are employees or contractors, and so on. But drones are a different matter, because of the danger that flying robots pose to life and limb, and the existence of strict rules that govern the use of physical airspace. Their future will depend as much on decisions made by regulators as it does on technological advances. How will it play out?304

303 KREPS, supra note 58, at 3.

304 The Future of Drones Depends on Regulation, Not Just Technology, EcONOMist (June 10, 2017), https://www.economist.com/news/technologyquarterly/21723000-engineers-and-regulators-will-have-work-togetherensure-safety-drones-take. 
Historically, the answer-from bicycles 305 to cars 306 to airplanes307_has been that regulators outlaw or impede the ownership and/or use of disruptive technologies until the safety of the innovation is established and/or society accepts the risks attendant to a particular innovation, trading off its drawbacks with its benefits. That has been, and likely is, the regulatory trajectory for commercial drone firms.

But given the pace of the sharing and gig economy, defection is a tangible consequence of the type of inefficient ex ante (preemptive and precautionary) regulation that has weighed down the commercial UAV segment for almost a

305 See, e.g., State v. Yopp, 97 N.C. 477 (1887). A bicyclist was charged with unlawfully riding a bicycle without state permission. The law required bicyclists to obtain permission from the superintendent of a road because "the use of the bicycle on the road materially interfered with the exercise of the rights and safety of others in the lawful use of their carriages and horses in passing over the road." Id. at 481. In upholding the exercise of this state police power, the North Carolina Supreme Court subordinated the right of Yopp to use his bicycle to the peril it presented other people and traffic. Id.

306 See, e.g., Lewis v. Amorous, 59 S.E. 338, 340 (Ga. App. 1907). Litigation centered on whether "automobiles [should be] classed with ferocious animals, and that the law relating to the duty of the owners of such animals is to be applied." Id. The court-many of whose judges had never owned a car-noted that the technology was neither good nor bad without context:

It is not the ferocity of automobiles that is to be feared, but the ferocity of those who drive them. Until human agency intervenes, they are usually harmless. While by reason of the rate of pay allotted to judges in this state few, if any, of them have ever owned one of these machines, yet some of them have occasionally ridden in them, thereby acquiring some knowledge of them; and we have, therefore, found out that there are times when these machines, not only lack ferocity, but assume such an indisposition to go that it taxes the limits of human ingenuity to make them move at all. [Automobiles] are not to be classed with bad dogs, vicious bulls, evil disposed mules, and the like.

Id.

307 Early courts characterized aviation an ultra-hazardous activity to which the doctrine of res ipsa loquitur applied. See generally, e.g., Northwest Airlines, Inc. v. Rowe, 226 F.2d 365 (8th Cir. 1955). 
decade. 308 In 2013, for example, USA Today reported about an underground drone economy taking flight in the absence of regulations in the United States.309 In 2014, DHL, unable to get authorization to test its drone (carrying medicine) in the United States, simply arranged to fly in Germany instead. 310 Amazon did the same in Canada, as did Google in Australia. 311 Private-public partnerships, meanwhile, are favored arrangements for stakeholders and regulators to address regulatory concerns tied to emerging technologies collaboratively, but consensus and agreement is elusive. 312 Worse, the federal government's farming out the difficult task of establishing drone regulations to private companies may be leaving startups and smaller "[c]ompanies that ultimately don't join any of the FAA's drone-related committees [to] fear that the agency is playing kingmaker in allowing certain companies advance control of the airspace." 313 Finally, and most recently, reports in 2017 that a federal drone advisory

308 This is occurring in the context of self-driving cars as Uber Technologies "defiantly offered rides to San Francisco customers in a handful of autonomous vehicles despite opposition from California regulators who demand the company get a state permit [under decades-old taxi laws] or pull the autos off the road." Greg Bensinger \& Tim Higgins, Uber's Clash with Regulators Moves to Self-Driving Cars, WALL ST. J. (Dec. 18, 2016, 2:49 PM), https://www.wsj.com/articles/ubers-clash-withregulators-moves-to-self-driving-cars-1482090589.

309 See Alistair Barr \& Elizabeth Weise, Underground Drone Economy Takes Flight, USA TODAY (Dec. 2, 2013, 8:04 PM), https://www.usatoday.com/story/tech/2013/12/02/underground-droneeconomy/3805387/ [perma.cc/RR5J-P34Y].

310 See Mark Scott, DHL to Begin Deliveries by Drone in Germany, N.Y. Times (Sept. 25, 2014, 6:20 AM), https://bits.blogs.nytimes.com/2014/09/25/dhl-to-begin-deliveries-by-dronein-germany/ [perma.cc/4DEM-3KWP] ("In the world of drones, Europe is out to show that whatever the United States can do, it can do better.”).

311 Id

312 Andy Pasztor, FAA Panel Splits on Drone Tracking Requirements, WALL ST. J. (Oct. 10, 2017, 12:54 PM), https:/www.wsj.com/articles/faapanel-splits-on-drone-tracking-requirements-1507654447.

313 Sally French, The Fight That's Roiling the Drone Industry: Small Businesses See an 'Ol' Boys Club' Forming, Drone GIRL (Nov. 11, 2017), http://thedronegirl.com/2017/11/11/fight-thats-roiling-drone-industrysmall-businesses-see-ol-boys-club-forming/ [perma.cc/8G8P-K2LX]. 
committee is poorly managed and has met in secret erodes confidence in a regulatory environment that will be fair, let alone quick, to adapt to the emerging UAV market.314

Rulemaking is not necessarily a linear process, of course. But, the early history of lawmaking in the arena of civil drones suggests a better way forwardfor drones and other technologies in the IoT. Perhaps: [T] he better alternative to a top down regulation is to deal with concerns creatively as they develop, using a combination of educational efforts, technological empowerment tools, social norms, public and watchdog pressure, industry best practices and selfregulation, transparency, and targeted enforcement of existing legal standards (especially torts), as needed. This bottom-up and layered approach to dealing with problems will not preemptively suffocate technological experimentation and innovation in these spaces. 315

Indeed, treating civil drones as a "permissionless innovation" may be appropriate whereby:

[E]xperimentation with new technologies and business models should generally be permitted by

314 See, e.g., Michael Lars, Federal Drone Advisory Panel Knocked for 'Lack of Transparency and Poor Management', WASH. Post (Nov. 8, 2017), https://www.washingtonpost.com/local/trafficandcommuting/federal-droneadvisory-panel-knocked-for-lack-of-transparency-and-poormanagement/2017/11/08/50393fb2-c4ae-11e7-84bc-

5e285c7f4512_story.html (quoting San Francisco Mayor Edwin M. Lee (D)) ("There is a stark imbalance of perspectives and viewpoints favoring industry interests at the expense of local and state governments and members of the public....Because the process was flawed, the recommendations produced by that process are also flawed."); Michael Lars, A U.S. Drone Advisory Group Has Been Meeting in Secret for Months. It Hasn't Gone Well., WAsH. Post (Oct. 23, 2017), https:/www.washingtonpost.com/local/trafficandcommuting/a-us-droneadvisory-group-has-been-meeting-in-secret-for-months-its-work-has-notgone-well/2017/10/23/f53106e0-6c01-11e7-b9e2-2056e768a7e5_story.html ("Melanie Sloan, a former federal prosecutor and senior adviser for the accountability group American Oversight, said the closed-door approach appears to violate open-meetings provisions of the Federal Advisory Committee Act.").

315 Thierer, supra note 20 , at $3-4$. 
default. Unless a compelling case can be made that a new invention will bring serious harm to individuals, innovation should be allowed to continue unabated, and problems-if they develop at all-can be addressed later. Permissionless innovation is not an absolutist position that denies any role for government. Rather, it is an aspirational goal that stresses the benefit of pushing "innovation allowed" as the best default position to begin debates about technology policy. The burden of proof is on those who favor preemptive, precautionary controls to explain why ongoing trial-and-error experimentation with new technologies or business models should be disallowed. 316

In the final analysis, treating civil drones exceptionally is inconsistent with the way regulators treat other contemporary innovations in transportation and bodes poorly for how regulators might approach technologies even more disruptive than drones. For example, automakers are not required to win pre-approval of self-driving vehicle technologies.317 Existing laws say almost nothing about personal flying machines such as those currently offered by startups such as Kitty Hawk. 318 And, in as soon as three years from now, a further regulatory challenge may arrive when Uber may be flying cars.319 The marketplace will not be well served if the precautionary regulatory configuration associated with civil drones prevails.

316 Id. at 39-40.

317 See, e.g., David Shepardson, Trump Meets Wireless, Drone Executives on New Technologies, ReUTERS (June 22, 2017. 2:10 PM), https://www.reuters.com/article/us-usa-trump-tech/trump-meets-wirelessdrone-executives-on-new-technologies-idUSKBN19D2DA [perma.cc/2XXRA6P9].

318 See KITTY HAwK, https://kittyhawk.aero/ [perma.cc/6VZ4-X5ZD]; see also Max Toomey, Ever Wanted to Ride a Giant Drone? Meet the Kitty Hawk Flyer., QUARTZ (May 8, 2017), https://qz.com/974870/ever-wanted-to-ride-agiant-drone-meet-the-kitty-hawk-flyer/ [perma.cc/CK9X-GEJ3].

319 Greg Bensinger, Uber Plans to Test Flying Cars Within Three Years, WALL ST. J. (Apr. 25, 2017, 2:58 PM), https://www.wsj.com/articles/uberplans-to-test-flying-cars-within-three-years-1493144437. 